\title{
Integrating faults and past earthquakes into a probabilistic seismic hazard model for peninsular Italy
}

\author{
Alessandro Valentini ${ }^{1}$, Francesco Visini ${ }^{2}$, and Bruno Pace ${ }^{1}$ \\ ${ }^{1}$ DiSPUTer, Università degli Studi “Gabriele d'Annunzio" Chieti-Pescara, Chieti, Italy \\ ${ }^{2}$ Istituto Nazionale di Geofisica e Vulcanologia, L'Aquila, Italy \\ Correspondence to: Alessandro Valentini (alessandro.valentini@unich.it)
}

Received: 27 January 2017 - Discussion started: 6 February 2017

Revised: 6 October 2017 - Accepted: 17 October 2017 - Published: 22 November 2017

\begin{abstract}
Italy is one of the most seismically active countries in Europe. Moderate to strong earthquakes, with magnitudes of up to $\sim 7$, have been historically recorded for many active faults. Currently, probabilistic seismic hazard assessments in Italy are mainly based on area source models, in which seismicity is modelled using a number of seismotectonic zones and the occurrence of earthquakes is assumed uniform. However, in the past decade, efforts have increasingly been directed towards using fault sources in seismic hazard models to obtain more detailed and potentially more realistic patterns of ground motion. In our model, we used two categories of earthquake sources. The first involves active faults, and using geological slip rates to quantify the seismic activity rate. We produced an inventory of all fault sources with details of their geometric, kinematic, and energetic properties. The associated parameters were used to compute the total seismic moment rate of each fault. We evaluated the magnitudefrequency distribution (MFD) of each fault source using two models: a characteristic Gaussian model centred at the maximum magnitude and a truncated Gutenberg-Richter model. The second earthquake source category involves grid-point seismicity, with a fixed-radius smoothed approach and a historical catalogue were used to evaluate seismic activity. Under the assumption that deformation is concentrated along faults, we combined the MFD derived from the geometry and slip rates of active faults with the MFD from the spatially smoothed earthquake sources and assumed that the smoothed seismic activity in the vicinity of an active fault gradually decreases by a fault-size-driven factor. Additionally, we computed horizontal peak ground acceleration (PGA) maps for return periods of 475 and 2475 years. Although the ranges and gross spatial distributions of the expected accelerations
\end{abstract}

obtained here are comparable to those obtained through methods involving seismic catalogues and classical zonation models, the spatial pattern of the hazard maps obtained with our model is far more detailed. Our model is characterized by areas that are more hazardous and that correspond to mapped active faults, while previous models yield expected accelerations that are almost uniformly distributed across large regions. In addition, we conducted sensitivity tests to determine the impact on the hazard results of the earthquake rates derived from two MFD models for faults and to determine the relative contributions of faults versus distributed seismic activity. We believe that our model represents advancements in terms of the input data (quantity and quality) and methodology used in the field of fault-based regional seismic hazard modelling in Italy.

\section{Introduction}

In this paper, we present the results of an alternative seismogenic source model for use in a probabilistic seismic hazard assessment (PSHA) for Italy that integrates active fault and seismological data. The use of active faults as an input for seismic hazard analysis is a consolidated approach in many countries characterized by high strain rates and seismic releases, as shown, for example, by Field et al. (2015) in California and Stirling et al. (2012) in New Zealand. Moreover, in recent years, active fault data have also been successfully integrated into seismic hazard studies or models in regions with moderate-to-low strain rates, such as SE Spain (e.g. GarciaMayordomo et al., 2007), France (e.g. Scotti et al., 2014), and central Italy (e.g. Peruzza et al., 2011). 
In Europe, a working group of the European Seismological Commission, named Fault2SHA, is discussing faultbased seismic hazard modelling (https://sites.google.com/ site/linkingfaultpsha/home). The working group, created to encourage exchange among field geologists, fault modellers, and seismic hazard practitioners, and it is a community initiative with long-term vision on studying the active faults. The work we are presenting here stems from the activities of the Fault2SHA working group.

Combining active faults and background sources is one of the key aspects in this type of approach. Although the methodology remains far from identifying a standard procedure, common approaches combine active faults and background sources by applying a threshold magnitude, generally between 5.5 and 7, above which seismicity is modelled as occurring on faults and below which seismicity is modelled via a smoothed approach (e.g. Akinci et al., 2009; Danciu et al., 2017), area sources (e.g. the so-called FSBG model in the 2013 European Seismic Hazard Model, ESHM13; Woessner et al., 2015), or a combination of the two (Field et al., 2015; Pace et al., 2006).

Another important aspect in the use of active faults to build a seismogenic source model is the use of an appropriate magnitude-frequency distribution (MFD) to characterize the temporal model describing the seismic activity of faults. Gutenberg-Richter (GR) and characteristic earthquake models are commonly used, and the choice sometimes depends on the knowledge of the fault and data availability. Often, the choice of the "appropriate" MFD for each fault source is a difficult task because palaeoseismological studies are scarce, and it is often difficult to establish clear relationships between mapped faults and historical seismicity. Recently, Field et al. (2017) discussed the effects and complexity of the choice, highlighting how often the GR model results are not consistent with data; however, in other cases, uncharacteristic behaviour, with rates smaller than the maximum, are possible. The discussion is open (see for example the discussion by Kagan et al., 2012) and far from being solved with the available observations, including both seismological and/or geological/palaeoseismological observations. In this work, we explore the calculations of these two MFDs, a characteristic Gaussian model and a truncated Gutenberg-Richter model, to explore the epistemic uncertainties and to consider a mixed model as a so-called "expert judgment" model. This mixed model approach, in which we assigned one of the two MFDs to each fault source, is useful for comparison analysis. The rationale of the choice of the MFD of each fault source is explained in detail later in this paper. However, this approach obviously does not solve this issue, which can be treated as epistemic uncertainties using logic tree or random sampling, but in any case, the choice of MFD remains an open question in fault-based PSHA.

In Italy, the current national PSH model for building code (Stucchi et al., 2011) is based on area sources and the classical Cornell approach (Cornell, 1968), in which the oc- currence of earthquakes is assumed uniform in the defined seismotectonic zones. However, we believe that more effort must be directed towards using geological data (e.g. fault sources and palaeoseismological information) in PSHA to use slip rates that describe longer seismic cycles to match the larger magnitudes, extending the observational time required to capture the recurrence of large-magnitude events and therefore improve the reliability of seismic hazard assessments. In fact, as highlighted by the 2016-2017 seismic sequences in central Italy, a zone-based source model is not able to model local spatial variations in ground motion (Meletti et al., 2016), whereas a fault-based model can provide insights for aftershock time-dependent hazard analysis (Peruzza et al., 2016). In conclusion, even if the main purpose of this work is to integrate active faults into hazard calculations for the Italian territory, this study does not represent an official update of the seismic hazard model of Italy.

\section{Source inputs}

Two earthquake-source inputs are considered in this work. The first is a fault source input that is based on active faults and uses the geometries and slip rates of known active faults to compute activity rates over a certain range of magnitudes. The second is a classical smoothed approach that accounts for the rates of expected earthquakes with a minimum moment magnitude $\left(M_{\mathrm{W}}\right)$ of 4.5 but excludes earthquakes associated with known faults based on a modified earthquake catalogue. Note that our seismogenic source requires the combination of the two source inputs related to the locations of expected seismicity rates into a single source model. Therefore, these two earthquake-source inputs are not independent but complementary, in both the magnitude and frequency distribution, and together account for spatial and temporal distribution of the seismicity in Italy.

In the following subsections, we describe the two source inputs and how they are combined in the seismogenic source model.

\subsection{Fault source input}

In seismic hazard assessment, an active fault is a structure that exhibits evidence of activity in the late Quaternary, has a demonstrable or potential capability of generating major earthquakes, and is capable of future reactivation (e.g. Machette, 2000; Danciu et al., 2017). The evidence of Quaternary activity can be geomorphological and/or palaeoseismological when activation information from instrumental seismic sequences and/or association with historical earthquakes is not available. Fault source data and location are useful for seismic hazard studies, and we compiled a database for Italy via the analysis and synthesis of neotectonic and seismotectonic data from approximately 90 published studies of 110 faults across Italy. Our database in- 
cluded, but was not limited to, the Database of Individual Seismogenic Sources (DISS vers. 3.2.0, http://diss.rm.ingv. $\mathrm{it} / \mathrm{diss} /$ ), which is already available for Italy. It is important to highlight that the DISS is currently composed of two main categories of seismogenic sources: individual and composite sources. The latter are defined by the DISS' authors as a "simplified and three-dimensional representation of a crustal fault containing an unspecified number of seismogenic sources that cannot be singled out. Composite seismogenic sources are not associated with a specific set of earthquakes or earthquake distribution", and therefore are not useful for our PSHA approach; the former is "a simplified and three-dimensional representation of a rectangular fault plane. Individual seismogenic sources are assumed to exhibit characteristic behaviour with respect to rupture length/width and expected magnitude" (http://diss.rm.ingv.it/ diss/index.php/about/13-introduction). Even if in agreement with our approach, we note that some of the individual seismogenic sources in the DISS are based on geological and palaeoseismological information, and many others used the Boxer code (Gasperini et al., 1999) to calculate the epicentre, moment magnitude, size, and orientation of a seismic source from observed macroseismic intensities. We carefully analysed the individual sources and some related issues: (i) the lack of updates to the geological information of some individual sources and (ii) the nonconformity between the input data used by DISS in Boxer and the latest historical seismicity (CPTI15) and macroseismic intensity (DBMI15) publications. Thus, we performed a full review of the fault database. We then compiled a fault source database as a synthesis of works published over the past 20 years, including DISS, using all updated and available geological, palaeoseismological, and seismological data (see Supplement for a complete list of references). We consider our database as complete as possible in terms of individual seismogenic sources, and it contains all the parameters necessary to construct an input data set for fault-based PSHA.

The resulting database of normal and strike-slip active and seismogenic faults in peninsular Italy (Fig. 1, Tables 1 and 2; see Supplement) includes all the available geometric, kinematic, slip rate, and earthquake source-related information. In the case of missing data regarding the geometric parameters of dip and rake, we assumed typical dip and rake values of 60 and $-90^{\circ}$ respectively for normal faults and 90 and 0 or $180^{\circ}$ respectively for strike-slip faults. In this paper, only normal and strike-slip faults are used as fault source inputs. We decided not to include thrust faults in the present study because, with the methodology proposed in this study (as discussed later in the text), the maximum size of a singlerupture segment must be defined, and segmentation criteria have not been established for large thrust zones. Moreover, our method uses long-term geological slip rates to derive active seismicity rates, and sufficient knowledge of these values is not available for thrust faults in Italy. Because some areas of Italy, such as the NE sector of the Alps, Po Valley, the

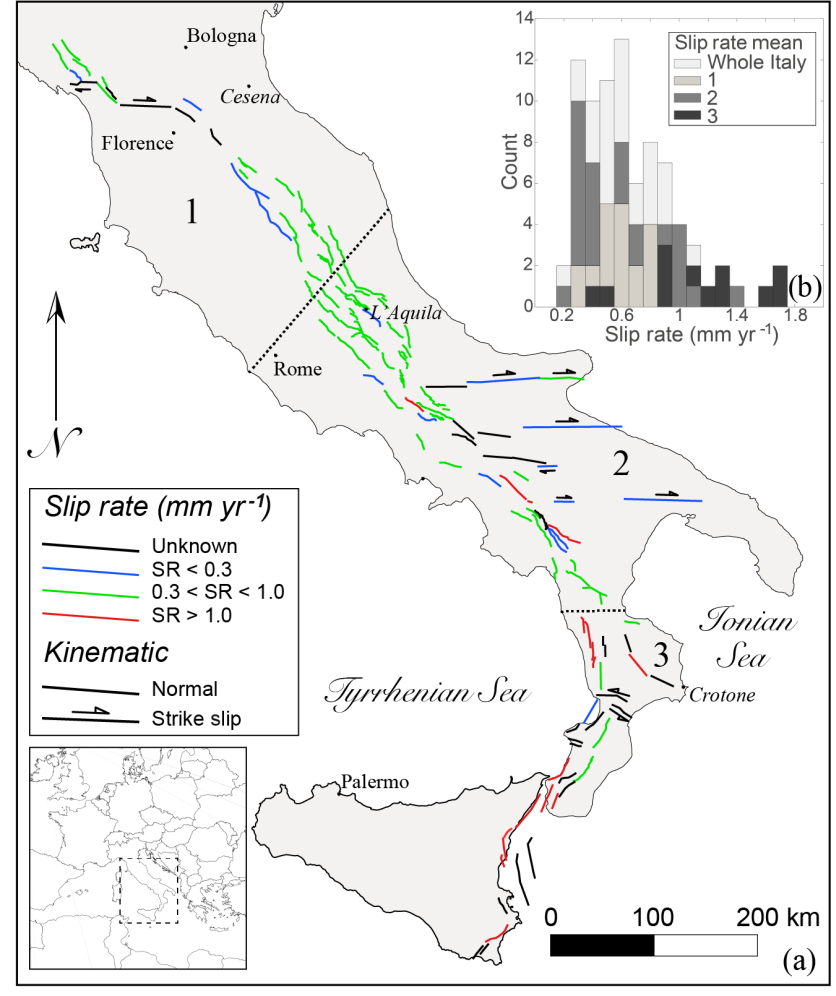

Figure 1. (a) Map of normal and strike-slip active faults used in this study. The colour scale indicates the slip rate. (b) Histogram of the slip rate distribution in the entire study area and in three subsectors. The numbers 1, 2, and 3 represent the northern Apennines, central-southern Apennines, and Calabrian-Sicilian coast regions respectively. The dotted black lines are the boundaries of the regions.

offshore sector of the central Adriatic Sea, and SW Sicily, may be excluded by this limitation, we are considering an update to our approach to include thrust faults and volcanic sources in a future study. The upper and lower boundaries of the seismogenic layer are mainly derived from the analysis of Stucchi et al. (2011) of the Italian national seismic hazard model and locally refined by more detailed studies (Boncio et al., 2011; Peruzza et al., 2011; Ferranti et al., 2014).

Based on the compiled database, we explored three main aspects associated with defining a fault source input: the slip rate evaluation, the segmentation model and the expected seismicity rate calculation.

\subsubsection{Slip rates}

Slip rates control fault-based seismic hazards (Main, 1996; Roberts et al., 2004; Bull et al., 2006; Visini and Pace, 2014) and reflect the velocities of the mechanisms that operate during continental deformation (e.g. Cowie et al., 2005). Moreover, long-term observations of faults in various tectonic contexts have shown that slip rates vary in space and time (e.g. Bull et al., 2006; Nicol et al., 2006, 2010; McClymont 
Table 1. Geometric parameters of the fault sources. $L$, along-strike length; dip, inclination angle of the fault plane; upper and lower, the thickness bounds of the local seismogenic layer; $\mathrm{SR}_{\min }$ and $\mathrm{SR}_{\max }$, the minimum and maximum slip rates assigned to the sources using the references available (see Supplement); and ID, the fault number identifier.

\begin{tabular}{|c|c|c|c|c|c|c|c|}
\hline ID & $\begin{array}{l}\text { Fault } \\
\text { sources }\end{array}$ & $\begin{array}{r}L \\
(\mathrm{~km})\end{array}$ & $\begin{array}{r}\text { Dip } \\
\left({ }^{\circ}\right)\end{array}$ & $\begin{array}{r}\text { Upper } \\
(\mathrm{km})\end{array}$ & $\begin{array}{r}\text { Lower } \\
(\mathrm{km})\end{array}$ & $\begin{array}{r}\mathrm{SR}_{\min } \\
\left(\mathrm{mm} \mathrm{yr}^{-1}\right)\end{array}$ & $\begin{array}{r}\mathrm{SR}_{\max } \\
\left(\mathrm{mm} \mathrm{yr}^{-1}\right)\end{array}$ \\
\hline 1 & Lunigiana & 43.8 & 40 & 0 & 5 & 0.28 & 0.7 \\
\hline 2 & North Apuane Transfer & 25.5 & 45 & 0 & 7 & 0.33 & 0.83 \\
\hline 3 & Garfagnana & 26.9 & 30 & 0 & 4.5 & 0.35 & 0.57 \\
\hline 4 & Garfagnana Transfer & 47.1 & 90 & 2 & 7 & 0.33 & 0.83 \\
\hline 5 & Mugello & 21.0 & 40 & 0 & 7 & 0.33 & 0.83 \\
\hline 6 & Ronta & 19.3 & 65 & 0 & 7 & 0.17 & 0.5 \\
\hline 7 & Poppi & 17.1 & 40 & 0 & 4.5 & 0.33 & 0.83 \\
\hline 8 & Città di Castello & 22.9 & 40 & 0 & 3 & 0.25 & 1.2 \\
\hline 9 & M.S.M. Tiberina & 10.5 & 40 & 0 & 2.5 & 0.25 & 0.75 \\
\hline 10 & Gubbio & 23.6 & 50 & 0 & 6 & 0.4 & 1.2 \\
\hline 11 & Colfiorito System & 45.9 & 50 & 0 & 8 & 0.25 & 0.9 \\
\hline 12 & Umbra Valley & 51.1 & 55 & 0 & 4.5 & 0.4 & 1.2 \\
\hline 13 & Vettore-Bove & 35.4 & 50 & 0 & 15 & 0.2 & 1.05 \\
\hline 14 & Nottoria-Preci & 29.0 & 50 & 0 & 12 & 0.2 & 1 \\
\hline 15 & Cascia-Cittareale & 24.3 & 50 & 0 & 13.5 & 0.2 & 1 \\
\hline 16 & Leonessa & 14.9 & 55 & 0 & 12 & 0.1 & 0.7 \\
\hline 17 & Rieti & 17.6 & 50 & 0 & 10 & 0.25 & 0.6 \\
\hline 18 & Fucino & 82.3 & 50 & 0 & 13 & 0.3 & 1.6 \\
\hline 19 & Sella di Corno & 23.1 & 60 & 0 & 13 & 0.35 & 0.7 \\
\hline 20 & Pizzoli-Pettino & 21.3 & 50 & 0 & 14 & 0.3 & 1 \\
\hline 21 & Montereale & 15.1 & 50 & 0 & 14 & 0.25 & 0.9 \\
\hline 22 & Gorzano & 28.1 & 50 & 0 & 15 & 0.2 & 1 \\
\hline 23 & Gran Sasso & 28.4 & 50 & 0 & 15 & 0.35 & 1.2 \\
\hline 24 & Paganica & 23.7 & 50 & 0 & 14 & 0.4 & 0.9 \\
\hline 25 & Middle Aternum Valley & 29.1 & 50 & 0 & 14 & 0.15 & 0.45 \\
\hline 26 & Campo Felice-Ovindoli & 26.2 & 50 & 0 & 13 & 0.2 & 1.6 \\
\hline 27 & Carsoli & 20.5 & 50 & 0 & 11 & 0.35 & 0.6 \\
\hline 28 & Liri & 42.5 & 50 & 0 & 11 & 0.3 & 1.26 \\
\hline 29 & Sora & 20.4 & 50 & 0 & 11 & 0.15 & 0.45 \\
\hline 30 & Marsicano & 20.0 & 50 & 0 & 13 & 0.25 & 1.2 \\
\hline 31 & Sulmona & 22.6 & 50 & 0 & 15 & 0.6 & 1.35 \\
\hline 32 & Maiella & 21.4 & 55 & 0 & 15 & 0.7 & 1.6 \\
\hline 33 & Aremogna C.Miglia & 13.1 & 50 & 0 & 15 & 0.1 & 0.6 \\
\hline 34 & Barrea & 17.1 & 55 & 0 & 13 & 0.2 & 1 \\
\hline 35 & Cassino & 24.6 & 60 & 0 & 11 & 0.25 & 0.5 \\
\hline 36 & Ailano-Piedimonte & 17.6 & 60 & 0 & 12 & 0.15 & 0.35 \\
\hline 37 & Matese & 48.3 & 60 & 0 & 13 & 0.2 & 1.9 \\
\hline 38 & Bojano & 35.5 & 55 & 0 & 13 & 0.2 & 0.9 \\
\hline 39 & Frosolone & 36.1 & 70 & 11 & 25 & 0.35 & 0.93 \\
\hline 40 & Ripabottoni-San Severo & 68.3 & 85 & 6 & 25 & 0.1 & 0.5 \\
\hline 41 & Mattinata & 42.3 & 85 & 0 & 25 & 0.7 & 1 \\
\hline 42 & Castelluccio dei Sauri & 93.2 & 90 & 11 & 22 & 0.1 & 0.5 \\
\hline 43 & Ariano Irpino & 30.1 & 70 & 11 & 25 & 0.35 & 0.93 \\
\hline 44 & Tammaro & 25.0 & 60 & 0 & 13 & 0.35 & 0.93 \\
\hline 45 & Benevento & 25.0 & 55 & 0 & 10 & 0.35 & 0.93 \\
\hline 46 & Volturno & 15.7 & 60 & 1 & 13 & 0.23 & 0.57 \\
\hline 47 & Avella & 20.5 & 55 & 1 & 13 & 0.2 & 0.7 \\
\hline 48 & Ufita-Bisaccia & 59.0 & 64 & 1.5 & 15 & 0.35 & 0.93 \\
\hline 49 & Melfi & 17.2 & 80 & 12 & 22 & 0.1 & 0.5 \\
\hline 50 & Irpinia Antithetic & 15.0 & 60 & 0 & 11 & 0.2 & 0.53 \\
\hline 51 & Irpinia & 39.7 & 65 & 0 & 14 & 0.3 & 2.5 \\
\hline 52 & Volturara & 23.7 & 60 & 1 & 13 & 0.2 & 0.35 \\
\hline
\end{tabular}


Table 1. Continued.

\begin{tabular}{|c|c|c|c|c|c|c|c|}
\hline ID & $\begin{array}{l}\text { Fault } \\
\text { sources }\end{array}$ & $\begin{array}{r}L \\
(\mathrm{~km})\end{array}$ & $\begin{array}{r}\text { Dip } \\
\left({ }^{\circ}\right)\end{array}$ & $\begin{array}{r}\text { Upper } \\
(\mathrm{km})\end{array}$ & $\begin{array}{r}\text { Lower } \\
(\mathrm{km})\end{array}$ & $\begin{array}{r}\mathrm{SR}_{\min } \\
\left(\mathrm{mm} \mathrm{yr}^{-1}\right)\end{array}$ & $\begin{array}{r}\mathrm{SR}_{\max } \\
\left(\mathrm{mm} \mathrm{yr}^{-1}\right)\end{array}$ \\
\hline 53 & Alburni & 20.4 & 60 & 0 & 8 & 0.35 & 0.7 \\
\hline 54 & Caggiano-Diano Valley & 46.0 & 60 & 0 & 12 & 0.35 & 1.15 \\
\hline 55 & Pergola-Maddalena & 50.6 & 60 & 0 & 12 & 0.20 & 0.93 \\
\hline 56 & Agri & 34.9 & 50 & 5 & 15 & 0.8 & 1.3 \\
\hline 57 & Potenza & 17.8 & 90 & 15 & 21 & 0.1 & 0.5 \\
\hline 58 & Palagianello & 73.3 & 90 & 13 & 22 & 0.1 & 0.5 \\
\hline 59 & Monte Alpi & 10.9 & 60 & 0 & 13 & 0.35 & 0.9 \\
\hline 60 & Maratea & 21.6 & 60 & 0 & 13 & 0.46 & 0.7 \\
\hline 61 & Mercure & 25.8 & 60 & 0 & 13 & 0.2 & 0.6 \\
\hline 62 & Pollino & 23.8 & 60 & 0 & 15 & 0.22 & 0.58 \\
\hline 63 & Castrovillari & 10.3 & 60 & 0 & 15 & 0.2 & 1.15 \\
\hline 64 & Rossano & 14.9 & 60 & 0 & 22 & 0.5 & 0.6 \\
\hline 65 & Crati West & 49.7 & 45 & 0 & 15 & 0.84 & 1.4 \\
\hline 66 & Crati East & 18.4 & 60 & 0 & 8 & 0.75 & 1.45 \\
\hline 67 & Lakes & 43.6 & 60 & 0 & 22 & 0.75 & 1.45 \\
\hline 68 & Fuscalto & 21.1 & 60 & 2 & 22 & 0.75 & 1.45 \\
\hline 69 & Piano Lago-Decollatura & 25.0 & 60 & 1 & 15 & 0.23 & 0.57 \\
\hline 70 & Catanzaro North & 29.5 & 80 & 3 & 20 & 0.75 & 1.45 \\
\hline 71 & Catanzaro South & 21.3 & 80 & 3 & 20 & 0.75 & 1.45 \\
\hline 72 & Serre & 31.6 & 60 & 0 & 15 & 0.7 & 1.15 \\
\hline 73 & Vibo & 23.0 & 80 & 0 & 15 & 0.75 & 1.45 \\
\hline 74 & Sant'Eufemia Gulf & 24.8 & 40 & 1 & 11 & 0.11 & 0.3 \\
\hline 75 & Capo Vaticano & 13.7 & 60 & 0 & 8 & 0.75 & 1.45 \\
\hline 76 & Coccorino & 13.3 & 70 & 3 & 11 & 0.75 & 1.45 \\
\hline 77 & Scilla & 29.7 & 60 & 0 & 13 & 0.8 & 1.5 \\
\hline 78 & Sant'Eufemia & 19.2 & 60 & 0 & 13 & 0.75 & 1.45 \\
\hline 79 & Cittanova-Armo & 63.8 & 60 & 0 & 13 & 0.45 & 1.45 \\
\hline 80 & Reggio Calabria & 27.2 & 60 & 0 & 13 & 0.7 & 2 \\
\hline 81 & Taormina & 38.7 & 30 & 3 & 13 & 0.9 & 2.6 \\
\hline 82 & Acireale & 39.4 & 60 & 0 & 15 & 1.15 & 2.3 \\
\hline 83 & Western Ionian & 50.1 & 65 & 0 & 15 & 0.75 & 1.45 \\
\hline 84 & Eastern Ionian & 39.3 & 65 & 0 & 15 & 0.75 & 1.45 \\
\hline 85 & Climiti & 15.7 & 60 & 0 & 15 & 0.75 & 1.45 \\
\hline 86 & Avola & 46.9 & 60 & 0 & 16 & 0.8 & 1.6 \\
\hline
\end{tabular}

et al., 2009a, b; Gunderson et al., 2013; Benedetti et al., 2013; D’Amato et al., 2016), and numerical simulations (e.g. Robinson et al., 2009; Cowie et al., 2012; Visini and Pace, 2014) suggest that variability mainly occurs in response to interactions between adjacent faults. Therefore, understanding the temporal variability in fault slip rates is a key point in understanding the earthquake recurrence rates and their variability.

To evaluate the minimum and maximum slip rates, which we assumed representative of the long-term slip rate variability over time, we used slip rates determined in different ways and at different timescales (e.g. at the decadal scale based on geodetic data or at longer scales based on the displacement of Holocene or Plio-Pleistocene horizons). These values were derived from approximately 65 available neotectonics, palaeoseismology, and seismotectonics papers (see Supplement). In this work, we used the mean of the minimum and maximum slip rate values listed in Table 1 and assumed that they are representative of the long-term behaviour (over the past $15 \mathrm{kyr}$ in the Apennines). Because a direct comparison of slip rates over different time intervals obtained by different methods may be misleading (Nicol et al., 2009), we cannot exclude the possibility that uncertainties and errors compilation could affect the original data in some cases. The discussion of these possible biases and their evaluation via statistically derived approaches (e.g. Gardner et al., 1987; Finnegan et al., 2014; Gallen et al., 2015) is beyond the scope of this paper and will be explored in future work. Moreover, we are assuming that slip rate values used are representative of seismic movements, and aseismic factors are not taken into account. Therefore, we believe that investigating the effect of this assumption could be another issue explored in future work, for example, by differentiating between aseismic slip factors in different tectonic contexts. 
Because 28 faults had no measured slip (or throw) rate (Fig. 1a), we proposed a statistically derived approach to assign a slip rate to these faults. Based on the slip rate spatial distribution shown in Fig. 1b, we subdivided the fault database into three large regions - the northern Apennines, central-southern Apennines, and Calabrian-Sicilian coast and analysed the slip rate distribution in these three areas. Figure $1 \mathrm{~b}$ indicates that the slip rates tend to increase from north to south. The fault slip rates in the northern Apennines range from 0.3 to $0.8 \mathrm{~mm} \mathrm{yr}^{-1}$, with the most common values ranging from approximately $0.5-0.6 \mathrm{~mm} \mathrm{yr}^{-1}$; the slip rates in the central-southern Apennines range from 0.3 to 1.0, and the most common rate is approximately $0.3 \mathrm{~mm} \mathrm{yr}^{-1}$; the slip rates in the southern area (Calabria and Sicily) range from 0.9 to 1.8 , with the most common being approximately $0.9 \mathrm{~mm} \mathrm{yr}^{-1}$.

Keeping in mind that average and minimum-maximum range of slip rate represents two different aspects of the slip rate behaviour of a fault (average long-term slip rate and its variability), we analysed them independently to assign values to active faults without measures.

The first step in assigning an average slip rate and a range of variability to the faults with unknown values is to identify the most representative distribution among known probability density functions using the slip rate data from each of the three areas. We test five well-known probability density functions (Weibull, normal, exponential, inverse Gaussian, and gamma) against mean slip rate observations. The resulting function with the highest log-likelihood is the normal function in all three areas. Thus, the mean value of the normal distribution is assigned to the faults with unknown values. We assign a value of $0.58 \mathrm{~mm} \mathrm{yr}^{-1}$ to faults in the northern area, $0.64 \mathrm{~mm} \mathrm{yr}^{-1}$ to faults in the central-southern area, and $1.10 \mathrm{~mm} \mathrm{yr}^{-1}$ to faults in the Calabrian-Sicilian area. To assign a range of slip rate variability to each of the three areas, we test the same probability density functions against slip rate variability observations. Similar to the mean slip rate, the probability density function with the highest log-likelihood is the normal function in all three areas. We assign a variability of $0.25 \mathrm{~mm} \mathrm{yr}^{-1}$ to the faults in the northern area, $0.29 \mathrm{~mm} \mathrm{yr}^{-1}$ to the faults in the central-southern area, and $0.35 \mathrm{~mm} \mathrm{yr}^{-1}$ to the faults in the Calabrian-Sicilian area.

\subsubsection{Segmentation rules for delineating fault sources}

An important issue in the definition of fault source input is the formulation of segmentation rules. In fact, the question of whether structural segment boundaries along multi-segment active faults act as persistent barriers to a single rupture is critical to defining the maximum seismogenic potential of fault sources. In our case, the rationale behind the definition of a fault source is based on the assumption that the geometric and kinematic features of a fault source are expressions of its seismogenic potential and that its dimensions are compatible for hosting major $\left(M_{\mathrm{w}} \geq 5.5\right)$ earthquakes. Therefore, a fault source may consist of a fault or an ensemble of faults that slip together during an individual major earthquake. A fault source is defined by a seismogenic master fault and its surface projection (Fig. 2a). Seismogenic master faults are separated from each other by first-order structural or geometrical complexities. Following the suggestions by Boncio et al. (2004) and Field et al. (2015), we imposed the following segmentation rules in our case study: (i) $4 \mathrm{~km}$ fault gaps among aligned structures; (ii) intersections with cross structures (often transfer faults) extending $4 \mathrm{~km}$ along strike and oriented at nearly right angles to the intersecting faults; (iii) overlapping or underlapping en echelon arrangements with separations between faults of $4 \mathrm{~km}$; (iv) bending $\geq 60^{\circ}$ for more than $4 \mathrm{~km}$; (v) average slip rate variability along a strike greater than or equal to $50 \%$; and (vi) changes in seismogenic thickness greater than $5 \mathrm{~km}$ among aligned structures. Example applications of the above rules are illustrated in Fig. 2a.

By applying the above rules to our fault database, the 110 faults yielded 86 fault sources: 9 strike-slip sources and 77 normal-slip sources. The longest fault source is Castelluccio dei Sauri (fault number, ID in Table 1, 42, $L=93.2 \mathrm{~km}$ ), and the shortest is Castrovillari (ID 63, $L=10.3 \mathrm{~km}$ ). The mean length is $30 \mathrm{~km}$. The dip angle varies from 30 to $90^{\circ}$, and $70 \%$ of the fault sources have dip angles between 50 and $60^{\circ}$. The mean value of seismogenic thickness (ST) is approximately $12 \mathrm{~km}$. The source with the largest ST is Mattinata (ID 41, ST $=25 \mathrm{~km}$ ), and the source with the thinnest ST is Monte Santa Maria Tiberina (ID 9, ST $=2.5 \mathrm{~km}$ ). This low value is due to the presence of an east-dipping low angle normal fault, the Alto-Tiberina Fault (Boncio et al., 2000), located a few kilometres west of the Monte Santa Maria Tiberina fault. Maximum observed moment magnitude values (MObs) have been assigned to 35 fault sources (based on Table 2), and the values vary from 5.90 to 7.32. The fault source inputs are shown in Fig. 3.

\subsubsection{Expected seismicity rates}

Each fault source is characterized by data, such as kinematic, geometry, and slip rate information, which we use as inputs for the FiSH code (Pace et al., 2016) to calculate the global budget of the seismic moment rate allowed by the structure. This calculation is based on predefined size-magnitude relationships in terms of the maximum magnitude $\left(M_{\max }\right)$ and the associated mean recurrence time $\left(T_{\text {mean }}\right)$. Table 1 summarizes the geometric parameters used as FiSH input parameters for each fault source (seismogenic box) shown in Fig. 3. To evaluate $M_{\max }$ of each source, according to Pace et al. (2016), we first computed and then combined up to five $M_{\max }$ estimates (see example of the Paganica fault source in Fig. 2b, details in Pace et al., 2016). Specifically, these five $M_{\max }$ estimates are as follows: MMo based on the calculated scalar seismic moment (Mo) and the application of the standard formula $M_{\mathrm{w}}=2 / 3(\log M o-9.1)$; Hanks and 
Table 2. Earthquake-source association adopted for fault sources. $I_{\mathrm{Max}}$, maximum intensity; $I_{0}$, epicentral intensity; $M_{\mathrm{w}}$, moment magnitude; and SD, standard deviation of the moment magnitude. For references, see Supplement.

\begin{tabular}{|c|c|c|c|c|c|c|c|c|}
\hline \multirow[b]{2}{*}{ ID } & \multirow[b]{2}{*}{ Fault sources } & \multicolumn{5}{|c|}{ Historical earthquakes } & \multicolumn{2}{|c|}{ Instrumental earthquakes } \\
\hline & & yyyy $/ \mathrm{mm} / \mathrm{dd}$ & $I_{\operatorname{Max}}$ & $I_{0}$ & $M_{\mathrm{W}}$ & SD & yyyy/mm/dd & $M_{\mathrm{W}}$ \\
\hline \multirow[t]{2}{*}{1} & Lunigiana & $1481 / 05 / 07$ & VIII & VIII & 5.6 & 0.4 & & \\
\hline & & $1834 / 02 / 14$ & IX & IX & 6.0 & 0.1 & & \\
\hline 2 & North Apuane Transfer & $1837 / 04 / 11$ & $\mathrm{X}$ & IX & 5.9 & 0.1 & & \\
\hline \multirow[t]{2}{*}{3} & Garfagnana & $1740 / 03 / 06$ & VIII & VIII & 5.6 & 0.2 & & \\
\hline & & $1920 / 09 / 07$ & $\mathrm{X}$ & $\mathrm{X}$ & 6.5 & 0.1 & & \\
\hline 4 & Garfagnana Transfer & & & & & & & \\
\hline \multirow[t]{2}{*}{5} & Mugello & $1542 / 06 / 13$ & IX & IX & 6.0 & 0.2 & & \\
\hline & & $1919 / 06 / 29$ & $\mathrm{X}$ & $\mathrm{X}$ & 6.4 & 0.1 & & \\
\hline 6 & Ronta & & & & & & & \\
\hline 7 & Poppi & & & & & & & \\
\hline \multirow[t]{4}{*}{8} & Città di Castello & 1269 & IX & IX & 5.7 & 0.5 & & \\
\hline & & $1389 / 10 / 18$ & VIII-IX & VIII-IX & 6 & 0.5 & & \\
\hline & & $1458 / 04 / 26$ & IX & IX & 5.8 & 0.1 & & \\
\hline & & $1789 / 09 / 30$ & & & 5.9 & & & \\
\hline \multirow[t]{2}{*}{9} & M.S.M. Tiberina & $1352 / 12 / 25$ & IX & IX & 6.3 & 0.2 & & \\
\hline & & $1917 / 04 / 26$ & IX-X & $\mathrm{IX}-\mathrm{X}$ & 6.0 & 0.1 & & \\
\hline 10 & Gubbio & & & & & & $1984 / 04 / 29$ & 5.6 \\
\hline \multirow[t]{3}{*}{11} & Colfiorito System & $1279 / 04 / 30$ & $\mathrm{X}$ & IX & 6.2 & 0.2 & $1997 / 09 / 26$ & 5.7 \\
\hline & & $1747 / 04 / 17$ & IX & IX & 6.1 & 0.1 & $1997 / 09 / 26$ & 6 \\
\hline & & $1751 / 07 / 27$ & $\mathrm{X}$ & $\mathrm{X}$ & 6.4 & 0.1 & & \\
\hline \multirow[t]{3}{*}{12} & Umbra Valley & 1277 & $\mathrm{X}$ & VIII & 5.6 & 0.5 & & \\
\hline & & $1832 / 01 / 13$ & VIII & $X$ & 6.4 & 0.1 & & \\
\hline & & $1854 / 02 / 12$ & & VIII & 5.6 & 0.3 & & \\
\hline 13 & Vettore-Bove & & & & & & $2016 / 10 / 30$ & 6.5 \\
\hline \multirow[t]{6}{*}{14} & Nottoria-Preci & $1328 / 12 / 01$ & $\mathrm{X}$ & $\mathrm{X}$ & 6.5 & 0.3 & 1979/09/19 & 5.8 \\
\hline & & $1703 / 01 / 14$ & XI & XI & 6.9 & 0.1 & & \\
\hline & & $1719 / 06 / 27$ & VIII & VIII & 5.6 & 0.3 & & \\
\hline & & $1730 / 05 / 12$ & IX & IX & 6.0 & 0.1 & & \\
\hline & & $1859 / 08 / 22$ & VIII-IX & VIII-IX & 5.7 & 0.3 & & \\
\hline & & $1879 / 02 / 23$ & VIII & VIII & 5.6 & 0.3 & & \\
\hline \multirow[t]{2}{*}{15} & Cascia-Cittareale & $1599 / 11 / 06$ & IX & IX & 6.1 & 0.2 & & \\
\hline & & $1916 / 11 / 16$ & VIII & VIII & 5.5 & 0.1 & & \\
\hline 16 & Leonessa & & & & & & & \\
\hline \multirow[t]{2}{*}{17} & Rieti & $1298 / 12 / 01$ & $\mathrm{X}$ & IX-X & 6.3 & 0.5 & & \\
\hline & & $1785 / 10 / 09$ & VIII-IX & VIII-IX & 5.8 & 0.2 & & \\
\hline \multirow[t]{3}{*}{18} & Fucino & $1349 / 09 / 09$ & IX & IX & 6.3 & 0.1 & & \\
\hline & & $1904 / 02 / 24$ & IX & VIII-IX & 5.7 & 0.1 & & \\
\hline & & $1915 / 01 / 13$ & $\mathrm{XI}$ & XI & 7 & 0.1 & & \\
\hline 19 & Sella di Corno & & & & & & & \\
\hline 20 & Pizzoli-Pettino & $1703 / 02 / 02$ & $\mathrm{X}$ & $\mathrm{X}$ & 6.7 & 0.1 & & \\
\hline 21 & Montereale & & & & & & & \\
\hline \multirow[t]{2}{*}{22} & Gorzano & $1639 / 10 / 07$ & $\mathrm{X}$ & IX $-X$ & 6.2 & 0.2 & & \\
\hline & & $1646 / 04 / 28$ & IX & IX & 5.9 & 0.4 & & \\
\hline 23 & Gran Sasso & & & & & & & \\
\hline \multirow[t]{2}{*}{24} & Paganica & $1315 / 12 / 03$ & VIII & VIII & 5.6 & 0.5 & $2009 / 06 / 04$ & 6.3 \\
\hline & & $1461 / 11 / 27$ & $\mathrm{X}$ & $\mathrm{X}$ & 6.5 & 0.5 & & \\
\hline 25 & Middle Aternum Valley & & & & & & & \\
\hline 26 & Campo Felice-Ovindoli & & & & & & & \\
\hline 27 & Carsoli & & & & & & & \\
\hline 28 & Liri & & & & & & & \\
\hline 29 & Sora & $1654 / 07 / 24$ & $X$ & IX-X & 6.3 & 0.2 & & \\
\hline 30 & Marsicano & & & & & & & \\
\hline 31 & Sulmona & & & & & & & \\
\hline
\end{tabular}


Table 2. Continued.

\begin{tabular}{|c|c|c|c|c|c|c|c|c|}
\hline \multirow[b]{2}{*}{ ID } & \multirow[b]{2}{*}{ Fault sources } & \multicolumn{5}{|c|}{ Historical earthquakes } & \multicolumn{2}{|c|}{ Instrumental earthquakes } \\
\hline & & yyyy $/ \mathrm{mm} / \mathrm{dd}$ & $I_{\mathrm{Max}}$ & $I_{0}$ & $M_{\mathrm{W}}$ & SD & yyyy $/ \mathrm{mm} / \mathrm{dd}$ & $M_{\mathrm{W}}$ \\
\hline 32 & Maiella & & & & & & & \\
\hline 33 & Aremogna C.Miglia & & & & & & & \\
\hline 34 & Barrea & & & & & & $1984 / 05 / 07$ & 5.9 \\
\hline 35 & Cassino & & & & & & & \\
\hline 36 & Ailano-Piedimonte & & & & & & & \\
\hline 37 & Matese & $1349 / 09 / 09$ & $\mathrm{X}-\mathrm{XI}$ & $X$ & 6.8 & 0.2 & & \\
\hline 38 & Bojano & $1805 / 07 / 26$ & $\mathrm{X}$ & $\mathrm{X}$ & 6.7 & 0.1 & & \\
\hline 39 & Frosolone & $1456 / 12 / 05$ & $\mathrm{XI}$ & $\mathrm{XI}$ & 7 & 0.1 & & \\
\hline \multirow[t]{3}{*}{40} & Ripabottoni-San Severo & $1627 / 07 / 30$ & $\mathrm{X}$ & $\mathrm{X}$ & 6.7 & 0.1 & $2002 / 10 / 31$ & 5.7 \\
\hline & & $1647 / 05 / 05$ & VII-VIII & VII-VIII & 5.7 & 0.4 & & \\
\hline & & $1657 / 01 / 29$ & IX-X & VIII-IX & 6.0 & 0.2 & & \\
\hline \multirow[t]{3}{*}{41} & Mattinata & $1875 / 12 / 06$ & VIII & VIII & 5.9 & 0.1 & & \\
\hline & & $1889 / 12 / 08$ & VII & VII & 5.5 & 0.1 & & \\
\hline & & $1948 / 08 / 18$ & VII-VIII & VII-VIII & 5.6 & 0.1 & & \\
\hline \multirow[t]{3}{*}{42} & Castelluccio dei Sauri & $1361 / 07 / 17$ & $\mathrm{X}$ & IX & 6 & 0.5 & & \\
\hline & & $1560 / 05 / 11$ & VIII & VIII & 5.7 & 0.5 & & \\
\hline & & $1731 / 03 / 20$ & IX & IX & 6.3 & 0.1 & & \\
\hline \multirow[t]{2}{*}{43} & Ariano Irpino & $1456 / 12 / 05$ & IX & IX & 6.9 & 0.1 & & \\
\hline & & $1962 / 08 / 21$ & & & 6.2 & 0.1 & & \\
\hline 44 & Tammaro & $1688 / 06 / 05$ & $\mathrm{XI}$ & $\mathrm{XI}$ & 7 & 0.1 & & \\
\hline 45 & Benevento & & & & & & & \\
\hline 46 & Volturno & & & & & & & \\
\hline 47 & Avella & $1499 / 12 / 05$ & VIII & VIII & 5.6 & 0.5 & & \\
\hline \multirow[t]{2}{*}{48} & Ufita-Bisaccia & $1732 / 11 / 29$ & $\mathrm{X}-\mathrm{XI}$ & $\mathrm{X}-\mathrm{XI}$ & 6.8 & 0.1 & & \\
\hline & & $1930 / 07 / 23$ & $\mathrm{X}$ & $\mathrm{X}$ & 6.7 & 0.1 & & \\
\hline 49 & Melfi & $1851 / 08 / 14$ & $X$ & $X$ & 6.5 & 0.1 & & \\
\hline 50 & Irpinia Antithetic & & & & & & & \\
\hline \multirow[t]{4}{*}{51} & Irpinia & $1466 / 01 / 15$ & VIII-IX & VIII-IX & 6.0 & 0.2 & $1980 / 11 / 23$ & 6.8 \\
\hline & & $1692 / 03 / 04$ & VIII & VIII & 5.9 & 0.4 & & \\
\hline & & $1694 / 09 / 08$ & $\mathrm{X}$ & $\mathrm{X}$ & 6.7 & 0.1 & & \\
\hline & & $1853 / 04 / 09$ & IX & VIII & 5.6 & 0.2 & & \\
\hline 52 & Volturara & & & & & & & \\
\hline 53 & Alburni & & & & & & & \\
\hline 54 & Caggiano-Diano Valley & $1561 / 07 / 31$ & IX $-X$ & $X$ & 6.3 & 0.1 & & \\
\hline \multirow[t]{2}{*}{55} & Pergola-Maddalena & $1857 / 12 / 16$ & & & 6.5 & & & \\
\hline & & $1857 / 12 / 16$ & & & 6.3 & & & \\
\hline 56 & Agri & & & & & & & \\
\hline 57 & Potenza & $1273 / 12 / 18$ & VIII-IX & VIII-IX & 5.8 & 0.5 & $1990 / 05 / 05$ & 5.8 \\
\hline 58 & Palagianello & & & & & & & \\
\hline 59 & Monte Alpi & & & & & & & \\
\hline 60 & Maratea & & & & & & & \\
\hline 61 & Mercure & $1708 / 01 / 26$ & VIII-IX & VIII & 5.6 & 0.6 & 1998/09/09 & 5.5 \\
\hline 62 & Pollino & & & & & & & \\
\hline 63 & Castrovillari & & & & & & & \\
\hline 64 & Rossano & $1836 / 04 / 25$ & $\mathrm{X}$ & IX & 6.2 & 0.2 & & \\
\hline \multirow[t]{3}{*}{65} & Crati West & $1184 / 05 / 24$ & IX & IX & 6.8 & 0.3 & & \\
\hline & & $1870 / 10 / 04$ & $\mathrm{X}$ & IX-X & 6.2 & 0.1 & & \\
\hline & & $1886 / 03 / 06$ & VII-VIII & VII-VIII & 5.6 & 0.3 & & \\
\hline \multirow[t]{2}{*}{66} & Crati East & $1767 / 07 / 14$ & VIII-IX & VIII-IX & 5.9 & 0.2 & & \\
\hline & & $1835 / 10 / 12$ & $\mathrm{X}$ & IX & 5.9 & 0.3 & & \\
\hline 67 & Lakes & $1638 / 06 / 08$ & $\mathrm{X}$ & $X$ & 6.8 & 0.1 & & \\
\hline 68 & Fuscalto & $1832 / 03 / 08$ & $X$ & $X$ & 6.6 & 0.1 & & \\
\hline 69 & Piano Lago-Decollatura & & & & & & & \\
\hline 70 & Catanzaro North & $1638 / 03 / 27$ & & & 6.6 & & & \\
\hline
\end{tabular}


Table 2. Continued.

\begin{tabular}{|c|c|c|c|c|c|c|c|c|}
\hline \multirow[b]{2}{*}{ ID } & \multirow[b]{2}{*}{ Fault sources } & \multicolumn{5}{|c|}{ Historical earthquakes } & \multicolumn{2}{|c|}{ Instrumental earthquakes } \\
\hline & & yyyy $/ \mathrm{mm} / \mathrm{dd}$ & $I_{\mathrm{Max}}$ & $I_{0}$ & $M_{\mathrm{W}}$ & SD & yyyy $/ \mathrm{mm} / \mathrm{dd}$ & $M_{\mathrm{W}}$ \\
\hline 71 & Catanzaro South & $1626 / 04 / 04$ & $X$ & IX & 6.1 & 0.4 & & \\
\hline \multirow[t]{4}{*}{72} & Serre & $1659 / 11 / 05$ & $\mathrm{X}$ & $\mathrm{X}$ & 6.6 & 0.1 & & \\
\hline & & $1743 / 12 / 07$ & IX-X & VIII-IX & 5.9 & 0.2 & & \\
\hline & & $1783 / 02 / 07$ & $\mathrm{X}-\mathrm{XI}$ & $\mathrm{X}-\mathrm{XI}$ & 6.7 & 0.1 & & \\
\hline & & $1791 / 10 / 13$ & IX & IX & 6.1 & 0.1 & & \\
\hline 73 & Vibo & & & & & & & \\
\hline 74 & Sant'Eufemia Gulf & $1905 / 09 / 08$ & $\mathrm{X}-\mathrm{XI}$ & $\mathrm{X}-\mathrm{XI}$ & 7 & 0.1 & & \\
\hline 75 & Capo Vaticano & & & & & & & \\
\hline 76 & Coccorino & $1928 / 03 / 07$ & VIII & VII-VIII & 5.9 & 0.1 & & \\
\hline 77 & Scilla & & & & & & & \\
\hline 78 & Sant'Eufemia & $1894 / 11 / 16$ & IX & IX & 6.1 & 0.1 & & \\
\hline \multirow[t]{2}{*}{79} & Cittanova-Armo & $1509 / 02 / 25$ & IX & VIII & 5.6 & 0.4 & & \\
\hline & & $1783 / 02 / 05$ & $\mathrm{XI}$ & XI & 7.1 & 0.1 & & \\
\hline 80 & Reggio Calabria & & & & & & & \\
\hline 81 & Taormina & $1908 / 12 / 28$ & XI & XI & 7.1 & 0.2 & & \\
\hline 82 & Acireale & $1818 / 02 / 20$ & IX-X & IX-X & 6.3 & 0.1 & & \\
\hline 83 & Western Ionian & $1693 / 01 / 11$ & XI & XI & 7.3 & 0.1 & & \\
\hline 84 & Eastern Ionian & & & & & & & \\
\hline 85 & Climiti & & & & & & & \\
\hline 86 & Avola & & & & & & & \\
\hline
\end{tabular}

Kanamori, 1979; IASPEI, 2005); two magnitude estimates using the Wells and Coppersmith (1994) empirical relationships for the maximum subsurface rupture length (MRLD) and maximum rupture area (MRA); an estimate that corresponds to the MObs, if available; and an estimate (MASP, ASP for aspect ratio) computed by reducing the fault length input if the aspect ratio ( $W / L)$ is smaller than the value evaluated by the relation between the aspect ratio and rupture length of observed earthquake ruptures, as derived by Peruzza and Pace (2002; not in the case of Paganica in Fig. 2b). In some cases, the use of MObs was useful to better constrain the seismogenic potential of individual seismogenic sources. For this reason and to take into account MObs in the estimation of $M_{\max }$, for each source we (i) calculated the maximum expected magnitude $\left(M_{\max 1}\right)$ and the relative uncertainties using only the scaling relationships and (ii) compared the maximum of observed magnitudes of the earthquakes potentially associated with the fault. If MObs was within the range of $M_{\max } \pm 1$ standard deviation, we considered the value and recalculated a new $M_{\max }\left(M_{\max 2}\right)$ with a new uncertainty. If MObs was larger than $M_{\max 1}+1$ standard deviation, we reviewed the fault geometry and/or the earthquake-source association. Conversely, if MObs was lower then $M_{\max 1}-1$ standard deviation we considered a GR behaviour for that source, without using the MObs in the $M_{\max 2}$ calculation. As an example, for the Irpinia Fault (ID 51 in Tables 1 and 2), the characteristics of the 1980 earthquake $\left(M_{\mathrm{w}} \sim 6.9\right)$ can be used to evaluate $M_{\max }$ via comparison with the $M_{\max }$ derived from scaling relationships.
Because all the empirical relationships, as well as observed historical and recent magnitudes of earthquakes, are affected by uncertainties, the MomentBalance (MB) function of the FiSH code (Pace et al., 2016) was used to account for these uncertainties. MB computes a probability density function (PDF) for each magnitude derived from empirical relationships or observations and summarizes the results as a maximum magnitude value with a standard deviation. The uncertainties in the empirical scaling relationship, in FiSH, are taken from the studies of Wells and Coppersmith (1994), Peruzza and Pace (2002), and Leonard (2010). Currently, the uncertainty in magnitude associated with the seismic moment is fixed and set to 0.3 , whereas the catalogue defines the uncertainty in MObs. Moreover, to combine the evaluated maximum magnitudes, MB creates a probability curve for each magnitude by assuming a normal distribution (Fig. 2). We assumed a two-sided un-truncated normal distribution of magnitudes. MB subsequently sums the probability density curves and fits the summed curve to a normal distribution to obtain the mean of the maximum magnitude $M_{\max }$ and its standard deviation.

Thus, a unique $M_{\max }$ with a standard deviation is computed for each source, and this value represents the maximum rupture that is allowed by the fault geometry and the rheological properties.

Finally, to obtain the mean recurrence time of $M_{\max }$ (i.e. $\left.T_{\text {mean }}\right)$, we use the criterion of "segment seismic moment conservation" proposed by Field et al. (1999). This criterion divides the seismic moment that corresponds to $M_{\max }$ by the 

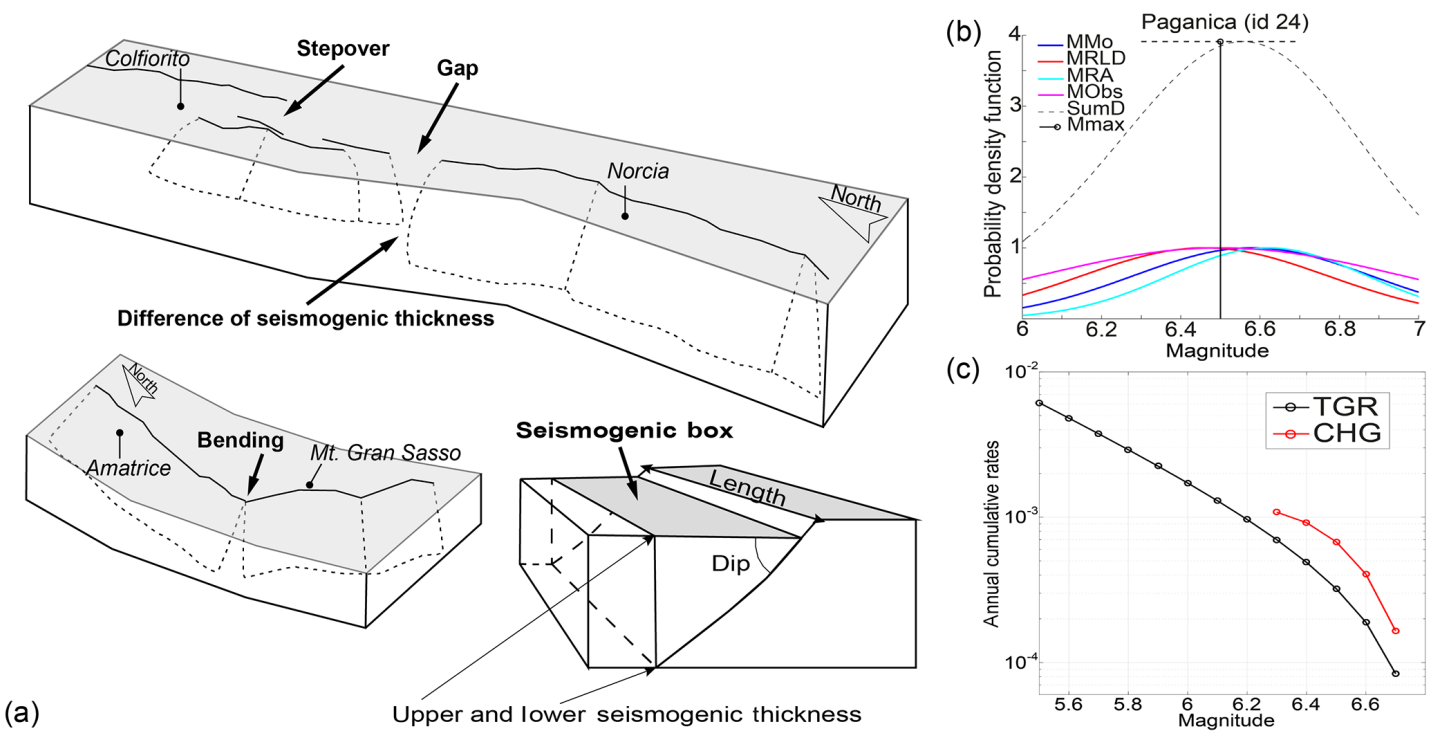

Figure 2. (a) Conceptual model of active faults and segmentation rules adopted to define a fault source and its planar projection, forming a seismogenic box (modified from Boncio et al., 2004). (b) Example of FiSH code output (see Pace et al., 2016, for details) for the Paganica fault source showing the magnitude estimates from empirical relationships and observations, both of which are affected by uncertainties. In this example, four magnitudes are estimated: MMo (blue line), based on the calculated scalar seismic moment (Mo), is from the standard formula (IASPEI, 2005); MRLD (red line) and MRA (cyan line) correspond to estimates based on the maximum subsurface fault length and maximum rupture area from the empirical relationships of Wells and Coppersmith (1994) for length and area respectively; and MObs (magenta line) is the largest observed moment magnitude. The black dashed line represents the summed probability density curve (SumD), the vertical black line represents the central value of the Gaussian fit of the summed probability density curve $\left(M_{\max }\right)$, and the horizontal black dashed line represents its standard deviation $\left(\sigma M_{\max }\right)$. The input values that were used to obtain this output are provided in Table 1. (c) Comparison of the magnitude-frequency distributions of the Paganica source, which were obtained using the CHG model (red line) and the TGR model (black line).

moment rate for given a slip rate:

$T_{\text {mean }}=\frac{1}{\text { Char_Rate }}=\frac{10^{\left(1.5 M_{\max }+9.1\right)}}{\mu \mathrm{VLW}}$,

where $T_{\text {mean }}$ is the mean recurrence time in years, Char_Rate is the annual mean rate of occurrence, $M_{\max }$ is the computed mean maximum magnitude, $\mu$ is the shear modulus, $V$ is the average long-term slip rate, and $L$ and $W$ are along-strike rupture length and down-dip width respectively. Finally, we calculated the seismic moment rate corresponding to $M_{\max }$ and the MFDs of expected seismicity. For each fault source, we use two endmember MFD models: (i) a characteristic Gaussian (CHG) model, a symmetric Gaussian curve (applied to the incremental MFD values) centred on the $M_{\max }$ value of each fault with a range of magnitudes equal to $1 \sigma$, and (ii) a truncated Gutenberg-Richter (TGR; Ordaz and Reyes, 1999; Kagan, 2002) model, with $M_{\max }$ as the upper threshold and $M_{\mathrm{w}}=5.5$ as the minimum threshold for all sources. We consider a constant $b$ value equal to 1.0 for all faults, as single-source events are insufficient for calculating the required statistics; this value corresponds to the mean $b$ value determined from the CPTI15 catalogue. The $a$ values were computed with the ActivityRate tool of the FiSH code. ActivityRate calculated activity rates at magnitudes given by each MFD, balancing the total MFD expected seismic moment rate with the seismic moment rate that was obtained based on $M_{\max }$ and $T_{\text {mean }}$ (details in Field et al., 1999, 2015; Pace et al., 2016; Woessner et al., 2015). In Fig. 2c, we show an example of the expected seismicity rates in terms of the annual cumulative rates for the Paganica source using the two above-described MFD models.

Finally, we create a so-called expert judgement model, called the mixed model, to determine the MFD for each fault source based on the earthquake-source associations. In this case, we decided that if an earthquake assigned to a fault source (see Table 2 for earthquake-source associations) has a magnitude lower than the magnitude range in the curve of the CHG model distribution, the TGR model is applied to that fault source. Otherwise, the CHG model, which peaks at the calculated $M_{\max }$, is applied. We decided to not use a logic tree for every fault to capture the model options because one of the aims of this work is to compare the different MFD choices in terms of results and impact in the hazard curves. Of course, errors in this approach can originate from the misallocation of historical earthquakes, and we cannot exclude the possibility that potentially active faults responsible for historical earthquakes have not yet been mapped. 


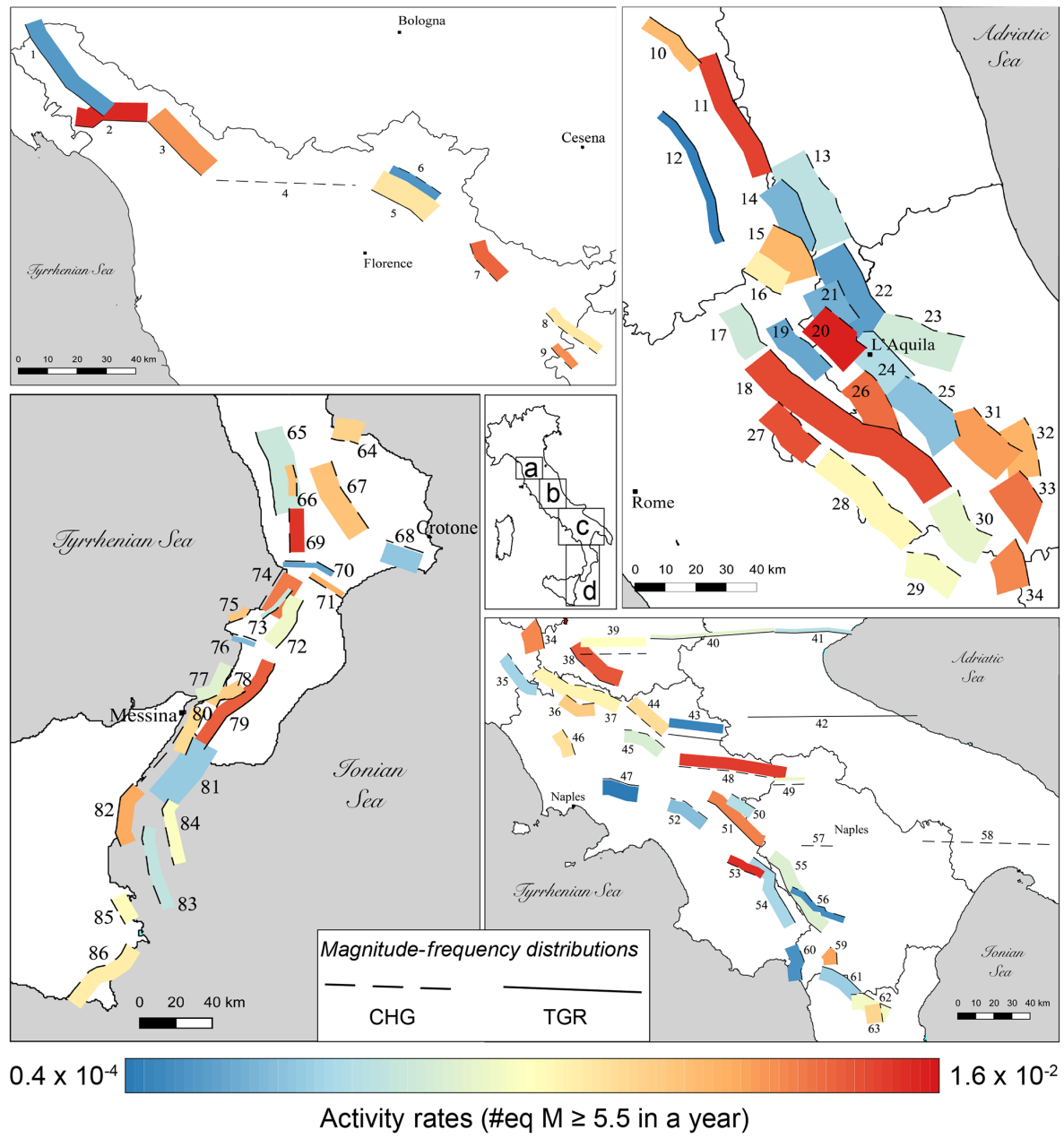

Figure 3. Maps showing the fault source inputs as seismogenic boxes (see Fig. 2a). The colour scale indicates the activity rate. Solid and dashed lines (corresponding to the uppermost edge of the fault) are used to highlight our choice between the two endmembers of the MFD model adopted in the so-called mixed model.

The MFD model assigned to each fault source in our mixed model is shown in Fig. 3.

\subsection{Distributed source inputs}

Introducing distributed earthquakes into the seismogenic source model is necessary because researchers have not been able to identify a causative source (i.e. a mapped fault) for important earthquakes in the historical catalogue. This lack of correlation between earthquakes and faults may be related to (i) interseismic strain accumulation in areas between major faults, (ii) earthquakes occurring on unknown or blind faults, (iii) earthquakes occurring on unmapped faults characterized by slip rates lower than the rates of erosional processes, and/or (iv) the general lack of surface ruptures associated with faults generating $M_{\mathrm{w}}<5.5$ earthquakes.

We used the historical catalogue of earthquakes (CPTI15; Rovida et al., 2016; Fig. 4) to model the occurrence of moderate-to-large $\left(M_{\mathrm{w}} \geq 4.5\right)$ earthquakes. The catalogue consists of 4427 events and covers approximately the last 1000 years from 1 January 1005 to 28 December 2014. Before using the catalogue, we removed all events not considered main shocks via a declustering filter (Gardner and Knopoff, 1974). This process resulted in a catalogue composed of 1839 independent events, which we denote as the "complete" catalogue. Moreover, to avoid double counting due to the use of two seismicity sources, i.e. the fault sources and the distributed seismicity sources, we removed events associated with known active faults from the CPTI15 earthquake catalogue. If the causative fault of an earthquake is known, that particular earthquake does not need to be included in the seismicity smoothing procedure. The earthquake-source association is based on neotectonics, palaeoseismology, and seismotectonics papers (see Supplement), and in a few cases, macroseismic intensity maps. In Table 2, we listed the earthquakes with known causative fault sources. The differences in the smoothed rates given 


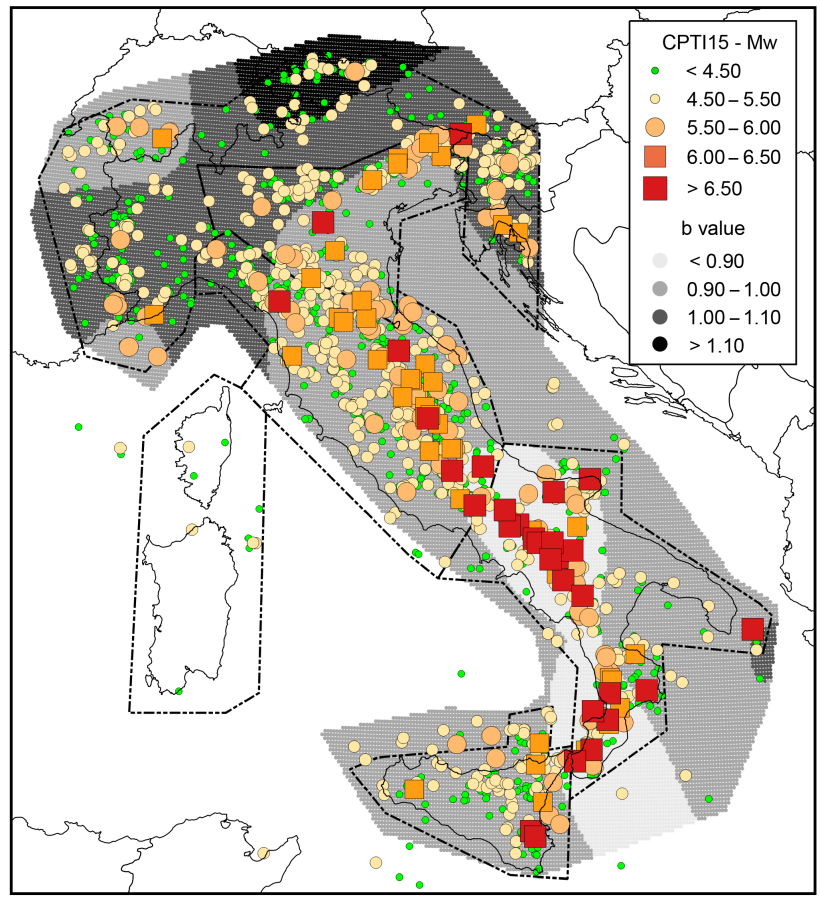

Figure 4. Historical earthquakes from the most recent version of the historical parametric Italian catalogue (CPTI15; Rovida et al., 2016), the spatial variations in $b$ values and the polygons defining the five macroseismic areas used to assess the magnitude completeness intervals (Stucchi et al., 2011).

by Eq. (2) using the complete and modified catalogues are shown in Fig. 5.

We applied the standard methodology developed by Frankel (1995) to estimate the density of seismicity in a grid with latitudinal and longitudinal spacing of $0.05^{\circ}$. The smoothed rate of events in each cell $i$ is determined as follows:

$n_{i}=\frac{\Sigma_{j} n_{j} e^{\frac{-\Delta_{i j}^{2}}{c^{2}}}}{\Sigma_{j} e^{\frac{-\Delta_{i j}^{2}}{c^{2}}}}$,

where $n_{i}$ is the cumulative rate of earthquakes with magnitudes greater than the completeness magnitude $M_{\mathrm{c}}$ in each cell $i$ of the grid, and $\Delta i j$ is the distance between the centres of grid cells $i$ and $j$. The parameter $c$ is the correlation distance. The sum is calculated in cells $j$ within a distance of $3 c$ of cell $i$.

To compute earthquake rates, we adopted the completeness magnitude thresholds over different periods given by Stucchi et al. (2011) for five large zones (Fig. 4).

To optimize the smoothing distance $\Delta$ in Eq. (2), we divided the earthquake catalogue into four 10-year disjoint learning and target periods from the 1960s to the 1990s. For each pair of learning and target catalogues, we used the probability gain per earthquake to find the optimal smoothing dis-

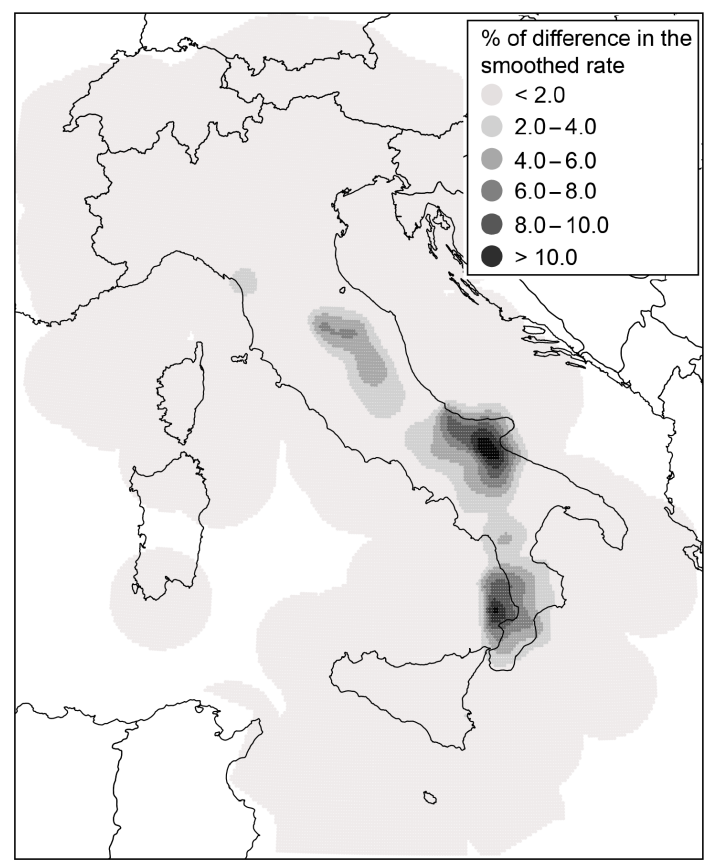

Figure 5. Differences in percentages between the two smoothed rates computed with Eq. (2) using the complete catalogue and the modified catalogue without events associated with known active faults (TGR model).

tance (Kagan and Knopoff, 1977; Helmstetter et al., 2007). After assuming a spatially uniform earthquake density model as a reference model, the probability gain per earthquake $G$ of a candidate model relative to a reference model is given by the following equation:

$G=\exp \left(\frac{L-L_{0}}{N}\right)$,

where $N$ is the number of events in the target catalogue and $L$ and $L_{0}$ are the joint log-likelihoods of the candidate model and reference model respectively. Under the assumption of a Poisson earthquake distribution, the joint log-likelihood of a model is given as follows:

$L=\sum_{i_{x}=1}^{N_{x}} \sum_{j_{y}=1}^{N_{y}} \log p\left[\lambda\left(i_{x}, i_{y}\right), \omega\right]$,

where $p$ is the Poisson probability, $\lambda$ is the spatial density, $\omega$ is the number of observed events during the target period, and the parameters $i_{x}$ and $i_{y}$ denote each corresponding longitude-latitude cell.

Figure 6 shows that for the four different pairs of learningtarget catalogues, the optimal smoothing distance $c$ (the mean curve) ranges from 25 to $40 \mathrm{~km}$. Finally, the mean of all the probability gains per earthquake yields a maximum smoothing distance of $30 \mathrm{~km}$ (Fig. 6), which is then used in Eq. (2).

The $b$ value of the GR distribution is calculated on a regional basis using the maximum-likelihood method of Weichert (1980), which allows for multiple periods with varying 


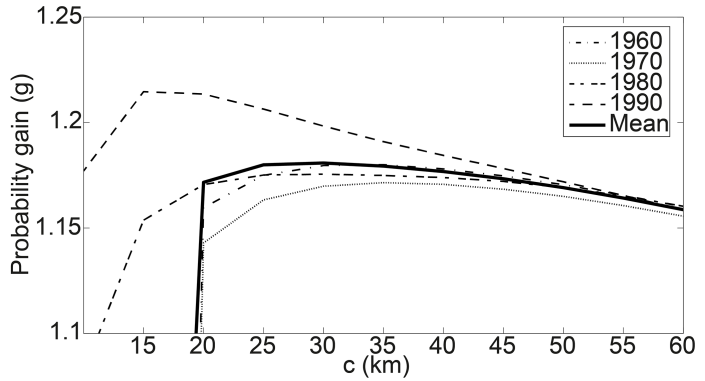

Figure 6. Probability gain per earthquake (see Eq. 3) versus correlation distance $c$, used to determine the best radius for use in the smoothed seismicity approach (Eq. 2).

completeness levels to be combined. Following the approach recently proposed by Kamer and Hiemer (2015), we used a penalized likelihood-based method for the spatial estimation of the GR $b$ values based on the Voronoi tessellation of space without tectonic dependency. The entire Italian territory has been divided into a grid with a longitude/latitude spacing of $0.05^{\circ}$, and the centres of the grid cells represent the possible centres of Voronoi polygons. We vary the number of Voronoi polygons, $N v$, from 3 to 50, generating 1000 tessellations for each $N v$. The summed log-likelihood of each obtained tessellation is compared with the log-likelihood given by the simplest model (prior model) obtained using the entire earthquake data set. We find that 673 random realizations led to better performance than the prior model. Thus, we calculate an ensemble model using these 673 solutions, and the mean $b$ value of each grid node is shown in Fig. 4.

The maximum magnitude $M_{\max }$ assigned to each node of the grid, the nodal planes, and the depths have been taken from ESHM13 (Woessner et al., 2015). The ESHM13 project evaluated the maximum magnitudes of large areas of Europe based on a joint procedure involving historical observations and tectonic regionalization. We adopted the lowest value of the maximum magnitude distributions proposed by ESHM13, but evaluating the impact of different maximum magnitudes is beyond the scope of this work.

Finally, the rates of expected seismicity for each node of the grid are assumed to follow the TGR model (Kagan, 2002):

$\lambda(M)=\lambda_{0} \frac{\exp (-\beta M)-\exp \left(-\beta M_{\mathrm{u}}\right)}{\exp \left(-\beta M_{0}\right)-\exp \left(-\beta M_{\mathrm{u}}\right)}$,

where the magnitude $(M)$ is in the range of $M_{0}$ (minimum magnitude) to $M_{\mathrm{u}}$ (upper or maximum magnitude); otherwise $\lambda(M)$ is 0 . Additionally, $\lambda_{0}$ is the smoothed rate of earthquakes at $M_{\mathrm{w}}=4.5$ and $\beta=b \ln (10)$.

\subsection{Combining fault and distributed sources}

To combine the two source inputs, we introduced a distancedependent linear weighting function, such that the contribution from the distributed sources linearly decreases from 1 to 0 with decreasing distance from the fault. The expected seismicity rates of the distributed sources start at $M_{\mathrm{w}}=4.5$, which is lower than the minimum magnitude of the fault sources, and the weighting function is only applicable in the magnitude range overlapping the MFD of each fault. This weighting function is based on the assumption that faults tend to modify the surrounding deformation field (Fig. 7), and this assumption is explained in detail later in this paper.

During fault system evolution, the increase in the size of a fault through linking with other faults results in an increase in displacement that is proportional to the quantity of strain accommodated by the fault (Kostrov, 1974). Under a constant regional strain rate, the activity of fault sections arranged across strike must eventually decrease (Nicol et al., 1997; Cowie, 1998; Roberts and Michetti, 2004). Using analogue modelling, Mansfield and Cartwrigth (2001) showed that faults grow via cycles of overlap, relay formation, breaching, and linkage between neighbouring segments across a wide range of scales. During the evolution of a system, the merging of neighbour faults, mostly along strike, results in the formation of major faults, which accommodate the majority of displacement. These major faults are surrounded by minor faults, which accommodate lower amounts of displacement. To highlight the spatial patterns of major and minor faults, Fig. $7 \mathrm{a}$ and $\mathrm{b}$ present diagrams from the Mansfield and Cartwright (2001) experiment in two different stages: the approximate midpoint of the sequence and the end of the sequence. Numerical modelling performed by Cowie et al. (1993) yielded similar evolutionary features for major and minor faults. The numerical fault simulation of Cowie et al. (1993) was able to reproduce the development of a normal fault system from the early nucleation stage, including interactions with adjacent faults, to full linkage and the formation of a large thoroughgoing fault. The model also captures the increase in the displacement rate of a large linked fault. In Fig. 7c and d, we focus on two stages of the simulation (from Cowie et al., 1993): the stage in which the fault segments have formed and some have become linked and the final stage of the simulation.

Notably, the spatial distributions of major and minor faults are very similar in the experiments of both Mansfield and Cartwrigth (2001) and Cowie et al. (1993), as shown in Fig. 7a-d. Developments during the early stage of major fault formation appear to control the location and evolution of future faults, with some areas where no major faults develop. The long-term evolution of a fault system is the consequence of the progressive cumulative effects of the slip history, i.e. earthquake occurrence, of each fault. Large earthquakes are generally thought to produce static and dynamic stress changes in the surrounding areas (King et al., 1994; Stein et al., 1994; Pace et al., 2014; Verdecchia and Carena, 2016). Static stress changes produce areas of negative stress, also known as shadow zones, and positive stress zones. The spatial distributions of decreases (unloading) and increases (loading) in stress during the long-term slip history of faults 
Mansfield and Cartwright (2001) analogue model

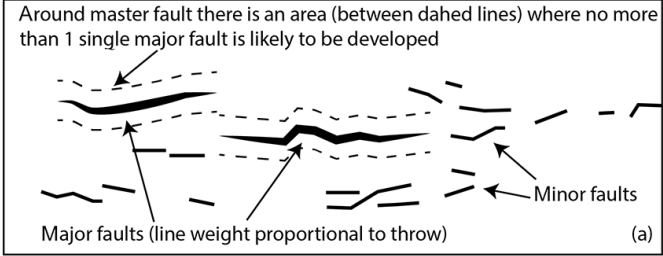

$\sim$ At half of the timeline evolution of the experiment

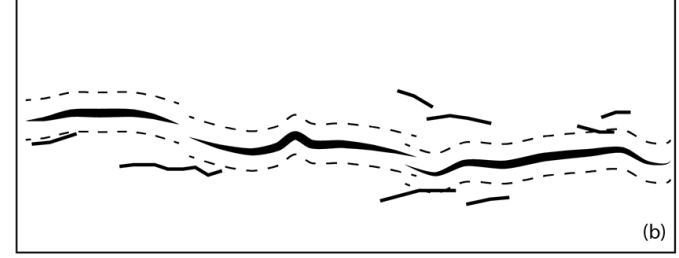

$\sim$ At end of the timeline evolution of the experiment

Cowie et al. (1993) numeric model

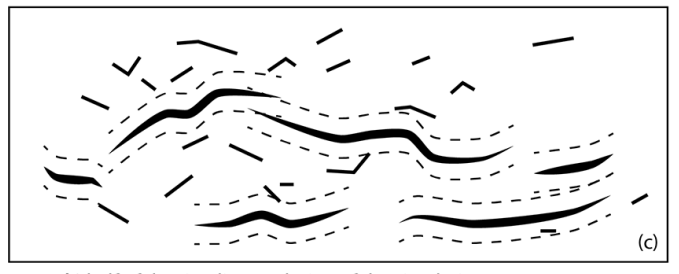

$\sim$ At half of the timeline evolution of the simulation

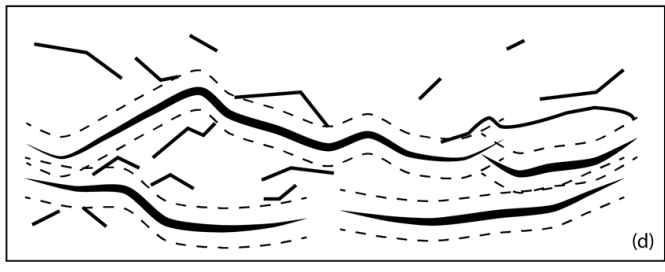

$\sim$ At end of the timeline evolution of the simulation

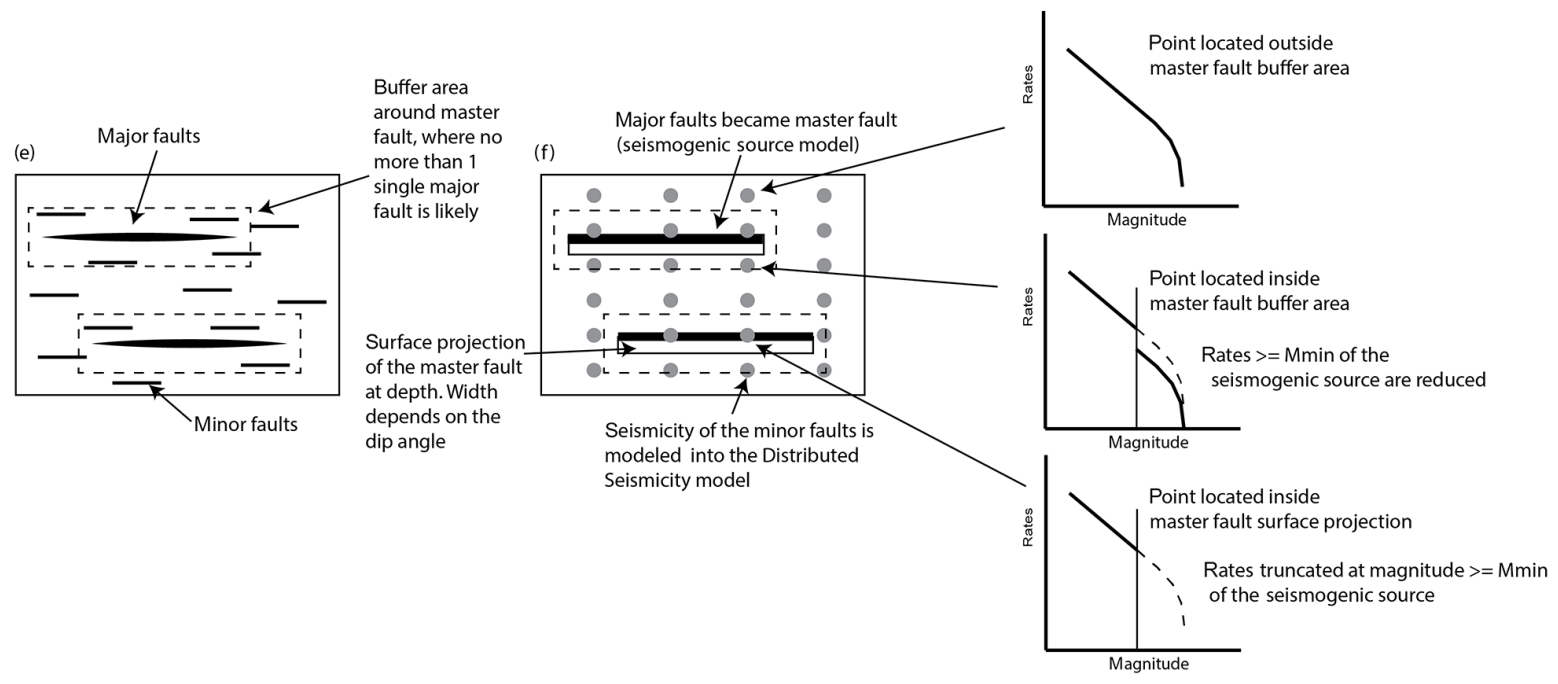

Figure 7. Fault system evolution and its implications for our model. (a, b) Diagrams from the Mansfield and Cartwright (2001) analogue experiment in two different stages: the approximate midpoint of the sequence and the end of the sequence. Areas exist around master faults where no more than a single major fault is likely to develop. (c, d) Diagrams from numerical modelling conducted by Cowie et al. (1993) in two different stages. This experiment shows the similar evolutional features of major and minor faults. (e, f) Application of the analogue and numerical modelling of fault system evolution to the fault source input proposed in this paper. A buffer area is drawn around each fault source, where it is unlikely for other major faults to develop, accounting for the length and slip rate of the fault source. This buffer area is useful for reducing or truncating the rates of expected distributed seismicity based on the position of a distributed seismicity point with respect to the buffer zone (see text for details).

likely influence the distance across strikes between major faults. Thus, given a known major active fault geometrically capable of hosting a $M_{\mathrm{w}} \geq 5.5$ earthquake, the possibility that a future $M_{\mathrm{w}} \geq 5.5$ earthquake will occur in the vicinity of the fault, but is not caused by that fault, should decrease as the distance from the fault decreases. Conversely, earthquakes with magnitudes lower than 5.5 and those due to slip along minor faults are likely to occur everywhere within a fault system, including in proximity to a major fault.
In Fig. 7e, we illustrate the results of the analogue and numerical modelling of fault system evolution and indicate the areas around major faults where it is unlikely that other major faults develop. In Fig. 7f, we show the next step in moving from geologic and structural considerations. In this step, we combine fault sources and distributed seismicity source inputs, which serve as inputs of the seismogenic model. Fault sources are used to model major faults and are represented by a master fault (i.e. one or more major faults) and its projec- 

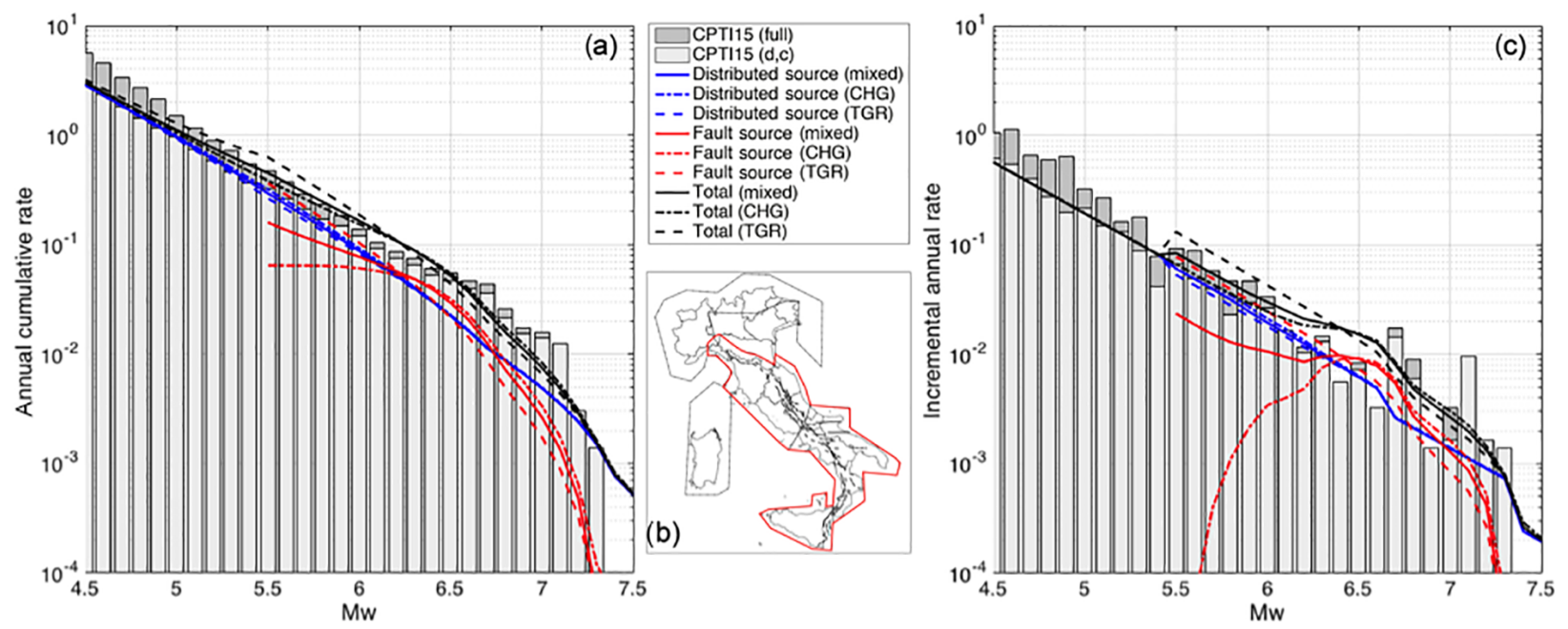

Figure 8. (a) Annual cumulative MFD and (c) incremental annual MFD computed for the red bounded area in (b). The rates have been computed using (i) the full CPTI15 catalogue; (ii) the declustered and complete catalogue (CPTI15, d, c in the legend) obtained using the completeness magnitude thresholds over different periods of time given by Stucchi et al. (2011) for five large zones; (iii) the distributed sources; (iv) the fault sources; and (v) summing fault and distributed sources (total).

tion at the surface. Distributed seismicity is used to model seismicity associated with minor, unknown, or unmapped faults. Depending on the positions of distributed seismicity points with respect to the buffer zones around major faults, the rates of expected distributed seismicity remain unmodified or decrease and can even reach zero.

Specifically, we introduced a slip rate and a distanceweighted linear function based on the above reasoning. The probability of the occurrence of an earthquake $\left(P_{\mathrm{e}}\right)$ with a $M_{\mathrm{w}}$ greater than or equal to the minimum magnitude of the fault is as follows:

$P_{\mathrm{e}}= \begin{cases}0, & d \leq 1 \mathrm{~km} \\ d / d_{\max }, & 1 \mathrm{~km}<d \leq d_{\max } \\ 1, & d>d_{\max },\end{cases}$

where $d$ is the Joyner-Boore distance from a fault source. The maximum value of $d\left(d_{\max }\right)$ is assumed to be controlled by the slip rate of the fault. For faults with slip rates $\geq 1 \mathrm{~mm} \mathrm{yr}^{-1}$, we assume $d_{\max }=L / 2(L$ is the length along the strike, Fig. 2a); for faults with slip rates of $0.3-$ $1 \mathrm{~mm} \mathrm{yr}^{-1}, d_{\max }=L / 3$; and for faults with slip rates of $\leq 0.3 \mathrm{~mm} \mathrm{yr}^{-1}, d_{\max }=L / 4$. The rationale for varying $d_{\max }$ is given by a simple assumption: the higher the slip rate is, the larger the deformation field and the higher the value of $d_{\max }$. This linear function has been applied around each fault, without differences between footwall and hanging wall. We applied Eq. (6) to the smoothed occurrence rates of the distributed seismogenic sources. In Fig. 8 we show the annual cumulative MFD (Fig. 8a) and incremental annual MFD (Fig. 8c) computed for the red bounded area in Fig. 8b. Because we consider three fault source inputs (red lines in Fig. 8): one using only TGR MFD; one using only CHG MFD; and one using mixed model MFD and because the
MFDs of distributed seismicity grid points in the vicinity of faults are modified with respect to the MFDs of these faults, we obtain three different inputs of distributed seismicity (blue lines in Fig. 8). These three distributed seismogenic source inputs differ because the minimum magnitude of the faults is $M_{\mathrm{W}} 5.5$ in the TGR model, but this value depends on each fault source dimension in the CHG and mixed model. From $M_{\mathrm{w}}=4.5$ to $M_{\mathrm{w}}=5.5$ the complete CPT15 is fully described by the MFD of the distributed source input. From $M_{\mathrm{w}}=5.5$ to $M_{\mathrm{w}}=6.3$ the total MFD (black lines in Fig. 8) computed using only TGR MFD is higher than the MFD computed using only CHG and mixed MFD; this is because the annual rates of occurrences of intermediate-magnitude events obtained with TGR model are higher than the ones obtained with CHG and mixed model, as shown in the incremental annual MFD in Fig. 8c. From $M_{\mathrm{w}}=6.4$ to $M_{\mathrm{w}}=7.3$ the total MFDs computed using only CHG and mixed MFD are higher the total MFD obtained with TGR model.

Our approach allows for incompleteness in the fault database to be bypassed, which is advantageous because all fault databases should be considered incomplete. In our approach, the seismicity is modified only in the vicinity of mapped faults. The remaining areas are fully described by the distributed input. With this approach, we do not define regions with reliable fault information, and the locations of currently unknown faults can be easily included when they are discovered in the future.

\section{Results and discussion}

To probabilistically obtain ground shaking, we assign the calculated seismicity rates, based on the Poisson hypothesis, to 


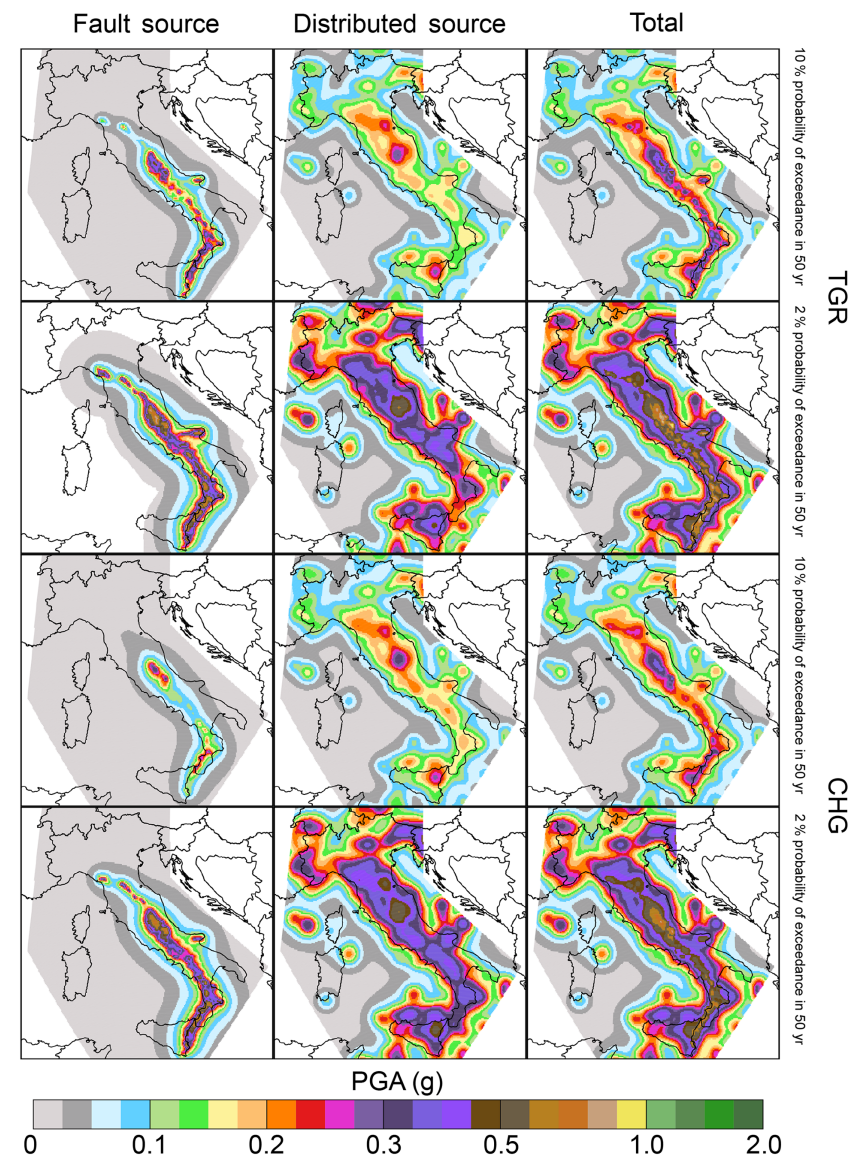

Figure 9. Seismic hazard maps for the TGR and CHG models expressed in terms of peak ground acceleration (PGA) and computed for a latitude-longitude grid spacing of $0.05^{\circ}$. The first and second rows show the fault source, distributed source, and total maps of the TGR model computed for $10 \%$ probability of exceedance in 50 years and $2 \%$ probability of exceedance in 50 years, corresponding to return periods of 475 and 2475 years respectively. The third and fourth rows show the same maps for the CHG model.

their pertinent geometries, i.e. individual 3-D seismogenic sources for the fault input and point sources for the distributed input (Fig. 8). All the computations are performed using the OpenQuake Engine, an open-source software developed recently with the purpose of providing seismic hazard and risk assessments (Pagani et al., 2014). Moreover, it is widely recognized within the scientific community for its potential. The ground motion prediction equations (GMPEs) of Akkar et al. (2013), Chiou and Youngs (2008), Faccioli et al. (2010) and Zhao et al. (2006) are used, because these GMPEs were selected in the ESHM13 (Woessner et al., 2015) for active shallow crust. In addition, we used the GMPE proposed by Bindi et al. (2014) and calibrated using Italian data. We combined all GMPEs into a logic tree with the same weight of 0.2 for each branch. Note that these GMPEs use different distance metrics: the Joyner-Boore dis-

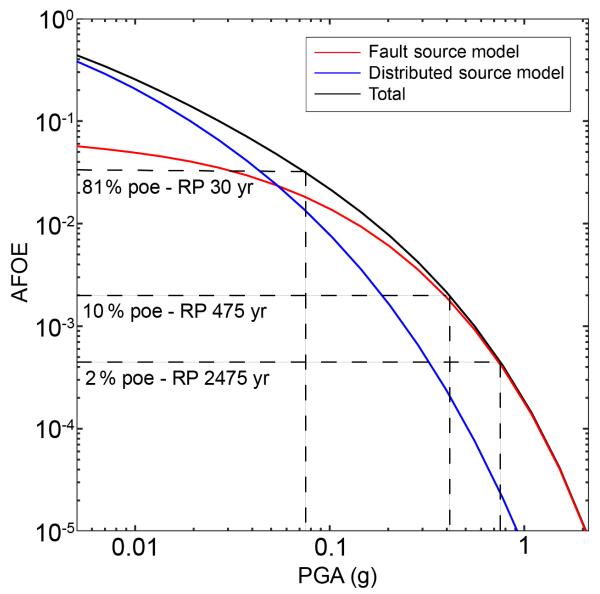

Figure 10. An example of the contribution to the total seismic hazard level (black line), in terms of hazard curves, by the fault (red line), and distributed (blue line) source inputs for one of the 45602 grid points (L'Aquila, 42.400, 13.400). The dashed lines represent the 2,10 , and $81 \%$ probabilities of exceedance (poe) in 50 years.

tance for Akkar et al. (2013), Bindi et al. (2014), and Chiou and Young (2008) and the closest rupture distance for Faccioli et al. (2010) and Zhao et al. (2006).

The results of the fault source inputs, distributed source inputs, and aggregated model are expressed in terms of peak ground acceleration (PGA) for exceedance probabilities of 10 and $2 \%$ over 50 years, corresponding to return periods of 475 and 2475 years respectively (Fig. 9).

To explore the epistemic uncertainty associated with the MFDs of fault source inputs, we compared the seismic hazard levels obtained based on the TGR and CHG fault source inputs (left column in Fig. 9) using the TGR and CHG MFDs for all the fault sources (details in Sect. 2.1.3). Although both models have the same seismic moment release, the different MFDs generate clear differences. In fact, for $10 \%$ exceedance probability in 50 years, in the TGR model all faults contribute significantly to the seismic hazard level, whereas in the CHG model, only a few faults located in the central Apennines and Calabria contribute to the seismic hazard level. This difference is due to the different shapes of the MFDs in the two models (Fig. 2c). As shown in Fig. 8, the amount of earthquakes with magnitudes between 5.5 and approximately 6 , which are likely the main contributors to these levels of seismic hazard, is generally higher in the TGR model than in the CHG model. At a $2 \%$ probability of exceedance in 50 years, all fault sources in the CHG contribute to the seismic hazard level, but the absolute values are still generally higher in the TGR model.

The distributed input (middle column in Fig. 9) depicts a more uniform shape of the seismic hazard level than that of fault source inputs. A PGA value lower than $0.125 \mathrm{~g}$ at a $10 \%$ probability of exceedance over 50 years and lower than $0.225 \mathrm{~g}$ at a $2 \%$ probability of exceedance over 50 years 


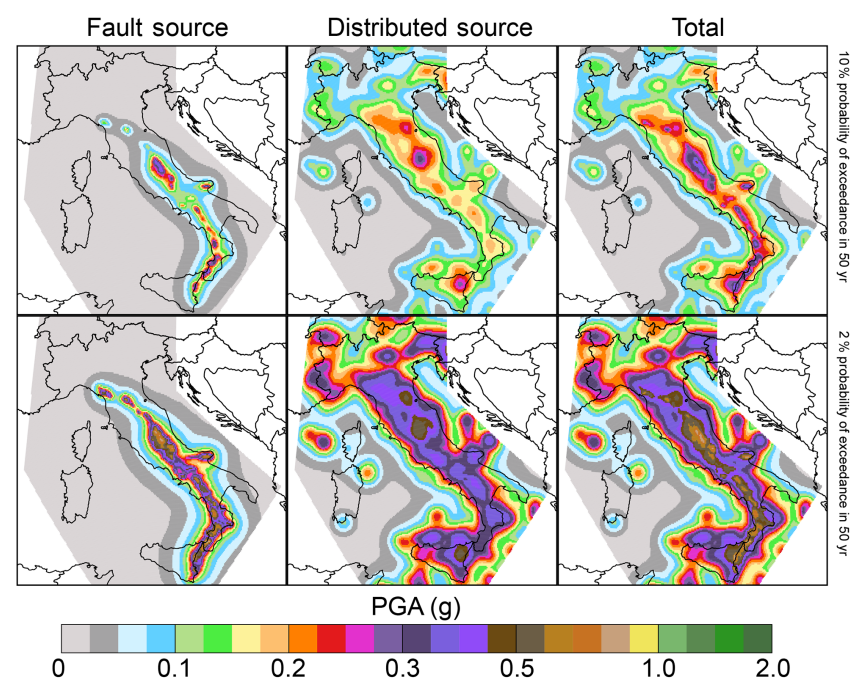

Figure 11. Seismic hazard maps for the mixed model. The first row shows the fault source, distributed source, and total maps computed for $10 \%$ probability of exceedance in 50 years, and the second row shows the same maps but computed for $2 \%$ probability of exceedance in 50 years, corresponding to return periods of 475 and 2475 years respectively. The results are expressed in terms of PGA.

encompass a large part of peninsular Italy and Sicily. Two areas with high levels of ground shaking are located in the central Apennines and northeastern Sicily.

The overall model, which was obtained by combining the fault and distributed source inputs, is shown in the right column of Fig. 9. Areas with comparatively high seismic hazard levels, i.e. hazard levels greater than $0.225 \mathrm{~g}$ and greater than $0.45 \mathrm{~g}$ at 50-year exceedance probabilities of 10 and $2 \%$ respectively are located throughout the Apennines, in Calabria, and in Sicily. The fault source inputs contribute most to the total seismic hazard levels in the Apennines, Calabria, and eastern Sicily, where the highest PGA values are observed.

Figure 10 shows the contribution to the total seismic hazard level by the fault and distributed source inputs at a specific site (L'Aquila, 42.400, 13.400). Notably, in Fig. 10, distributed sources dominate the seismic hazard contribution at exceedance probabilities greater than $\sim 81 \%$ over 50 years, but the contribution of fault sources cannot be neglected. Conversely, at exceedance probabilities of less than $\sim 10 \%$ in 50 years, the total hazard level is mainly associated with fault source inputs. Moreover, note that the contributions are not based on deaggregation but are computed according to the percentage of each source input in the annual frequency of exceedance (AFOE) value of the combined model.

Figure 11 presents seismic hazard maps for PGA at 10 and $2 \%$ exceedance probabilities in 50 years for fault sources, distributed sources, and a combination of the two. These data were obtained using the above-described mixed model, in which we selected the most appropriate MFD model (TGR or CHG) for each fault (as shown in Fig. 3). The results of

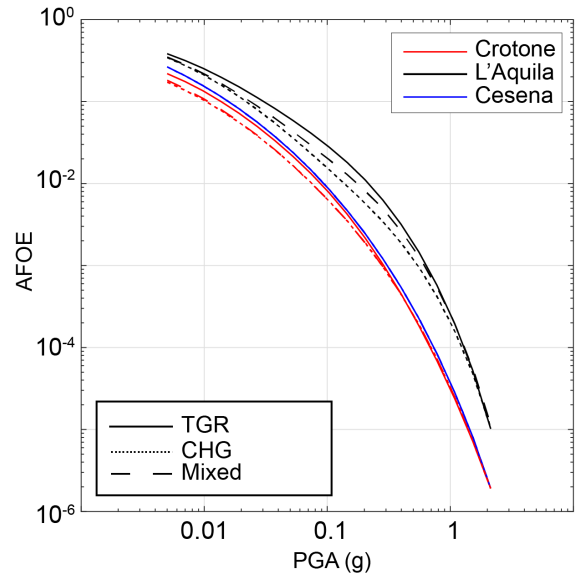

Figure 12. CHG (dotted line), TGR (solid line), and mixed model (dashed line) hazard curves for three sites (see Fig. 13 for the location): Cesena (red line), L'Aquila (black line), and Crotone (blue line)

this model therefore have values between those of the two endmembers shown in Fig. 9.

Figure 12 shows the CHG, TGR, and mixed model hazard curves of three sites (Cesena, L'Aquila, and Crotone, Fig. 13c). As previously noted, the results of the mixed model, due to the structure of the model, are between those of the CHG and TGR models. The relative positions of the hazard curves derived from the two endmember models and the mixed model depend on the number of nearby fault sources that have been modelled using one of the MFD models and on the distance of the site from the faults. For example, in the case of the Crotone site, the majority of the fault sources in the mixed model are modelled using the CHG MFD. Thus, the resulting hazard curve is similar to that of the $\mathrm{CHG}$ model. For the Cesena site, the three hazard curves overlap. Because the distance between Cesena and the closest fault sources is approximately $60 \mathrm{~km}$, the impact of the fault input is less than the impact of the distributed source input. In this case, the choice of a particular MFD model has a limited impact on the modelling of distributed sources. Notably, for an AFOE higher than $10^{-4}$, the TGR fault source input values are generally higher than those of the CHG source input, and the three models converge at AFOE lower than $10^{-4}$, as shown for L'Aquila site. The resulting seismic hazard estimates depend on the assumed MFD model (TGR vs. CHG), and for the investigated range of AFOE, especially on the annual rates of occurrences of intermediate-magnitude events (5.5 to $\sim 6.5$; see Fig. 8 ). Therefore, the TGR model leads to the highest hazard values because this range of magnitude ( 5.5 to $\sim 6.5$ ) contributes the most to the hazard level.

In Fig. 13, we investigated the influences of the mixed fault source inputs and the mixed distributed source inputs on the total hazard level of the entire study area, as well as the spatial variability. The maps in Fig. 13a show that the 


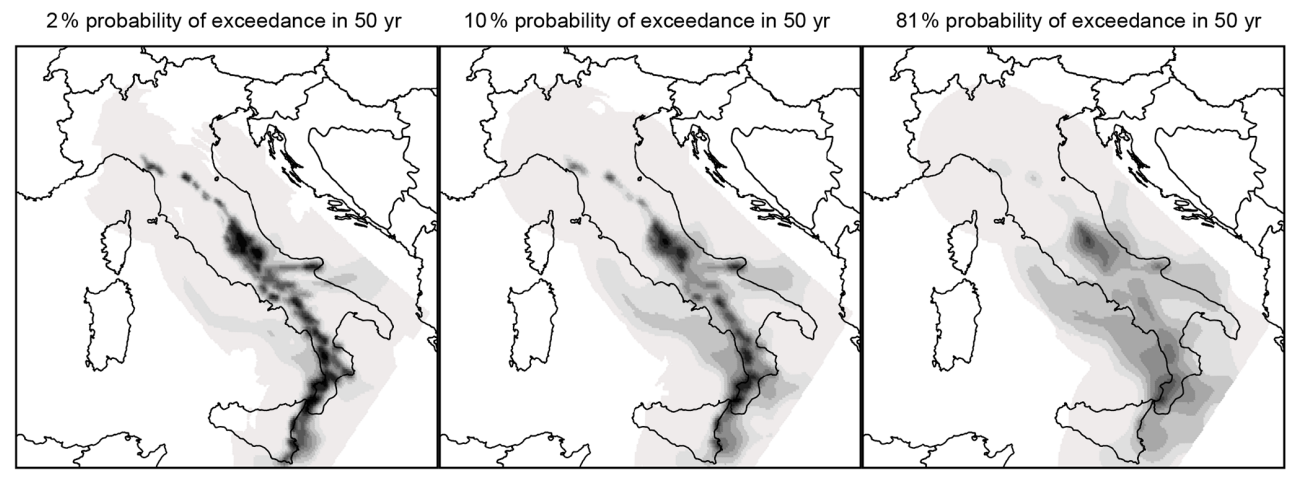

(a) $100 \%$

Distributed source model
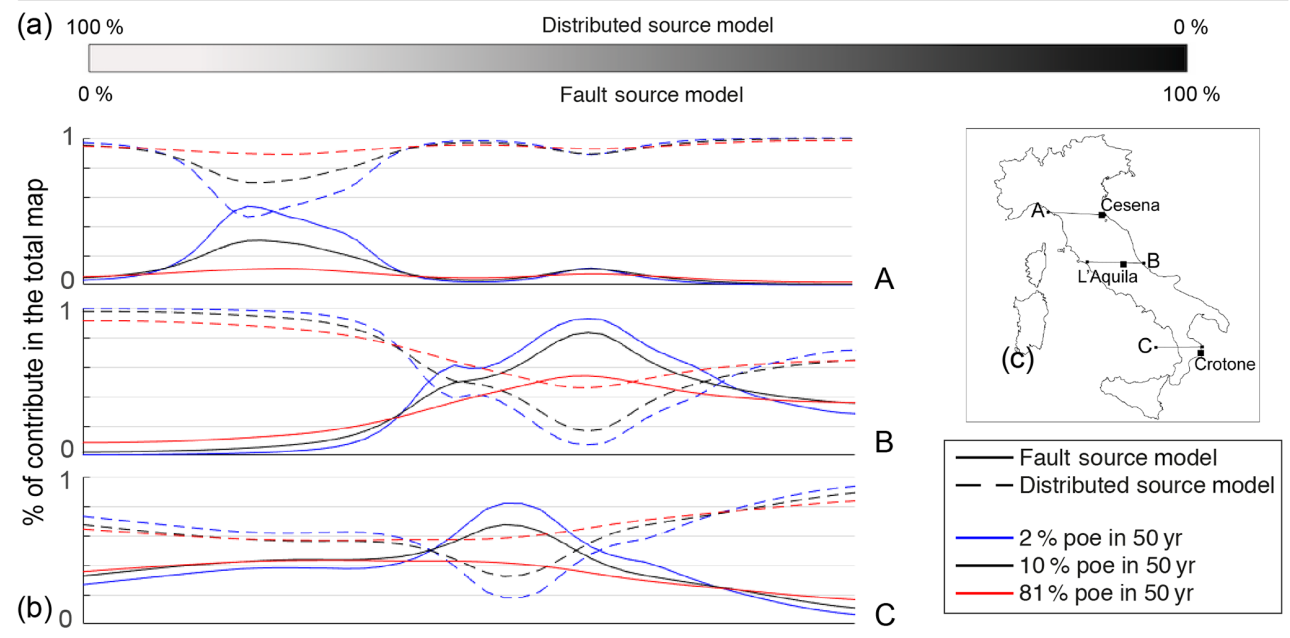

Figure 13. (a) Contribution maps of the mixed fault and distributed source inputs to the total hazard level for three probabilities of exceedance: 2,10 , and $81 \%$, corresponding to return periods of 2475, 475, and 30 years respectively. (b) Contributions of the mixed fault (solid line), and distributed (dashed line) source inputs along three profiles (A, B, and C in c) for three probabilities of exceedance: $2 \%$ (blue line), $10 \%$ (black line), and $81 \%$ (red line).

contribution of fault inputs to the total hazard level generally decreases as the exceedance probability increases from 2 to $81 \%$ in 50 years. At a $2 \%$ probability of exceedance in 50 years, the total hazard levels in the Apennines and eastern Sicily are mainly related to faults, whereas at an $81 \%$ probability of exceedance in 50 years, the contributions of fault inputs are high in local areas of central Italy and southern Calabria.

Moreover, we examined the contributions of fault and distributed sources along three E-W-oriented profiles in northern, central, and southern Italy (Fig. 13b). In areas with faults, the hazard level estimated by fault inputs is generally higher than that estimated by the corresponding distributed source inputs. Notable exceptions are present in areas proximal to slow-slipping active faults at an $81 \%$ probability of exceedance in 50 years (profile A), such as those at the eastern and western boundaries of the fault area in central Italy (profile B), and in areas where the contribution of the distributed source input is equal to that of the fault input at a $10 \%$ probability of exceedance in 50 years (eastern part of profile C).
The features depicted by the three profiles result from a combination of the slip rates and spatial distributions of faults for fault source inputs. The proposed approach requires a high level of expertise in active tectonics and cautious expert judgement at many levels in the procedure. First, the seismic hazard estimate is based on the definition of a segmentation model, which requires a series of rules based on observations and empirical regression between earthquakes and the size of the causative fault. New data might make it necessary to revise the rules or reconsider the role of the segmentation. In some cases, expert judgement could permit discrimination among different fault source models. Alternatively, all models should be considered branches in a logic tree approach.

Moreover, we propose a fault seismicity input in which the MFD of each fault source has been chosen based on an analysis of the occurrences of earthquakes that can be tentatively or confidently assigned to a certain fault. To describe the fault activity, we applied a probability density function to the magnitude, as commonly performed in the literature: the TGR model, where the maximum magnitude is the upper threshold and $M_{\mathrm{w}}=5.5$ is the lower threshold for all faults, and the characteristic maximum magnitude model, which con- 


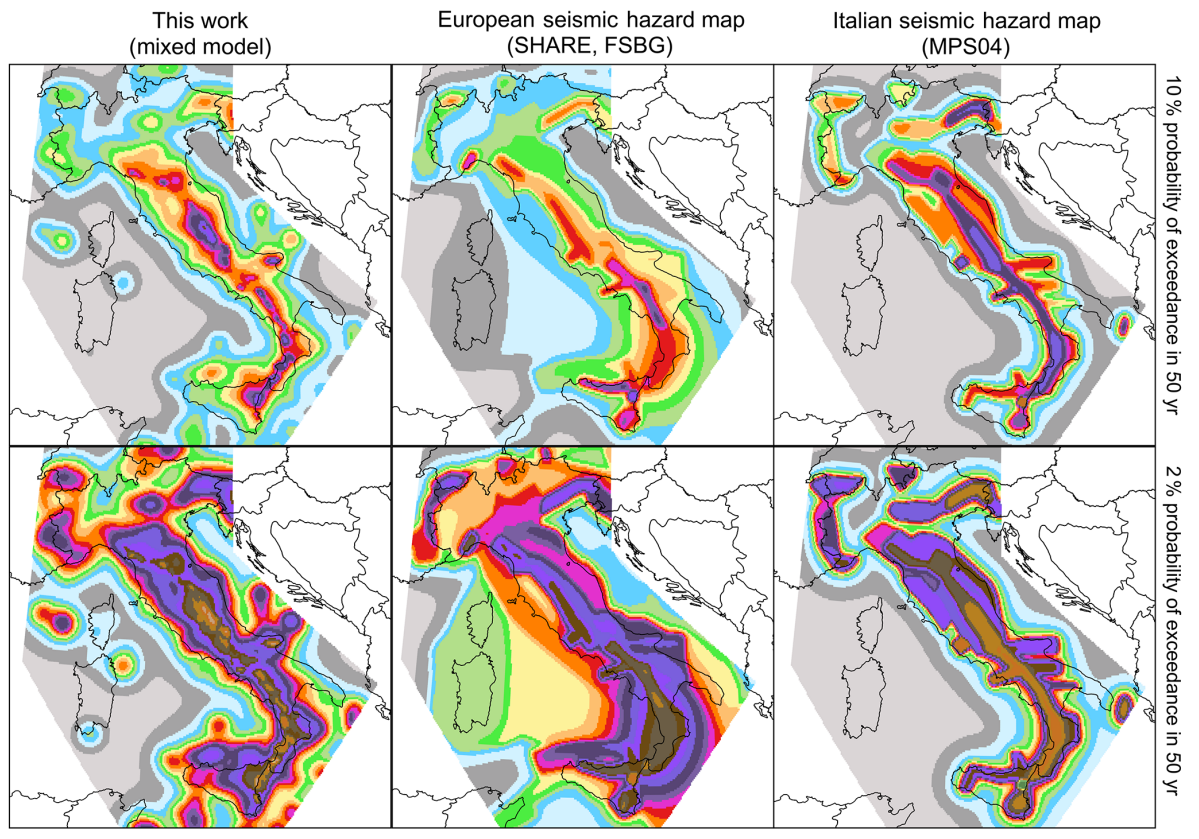

Figure 14. Seismic hazard maps expressed in terms of PGA and computed for a latitude-longitude grid spacing of $0.05^{\circ}$ based on rock site conditions. The figure shows a comparison of our model (mixed model, left column), the ESHM13 model (FSBG logic tree branch, middle column), and the current Italian national seismic hazard map (MPS04, right column). The same combination of GMPEs (Akkar et al., 2013; Chiou and Youngs, 2008; Faccioli et al., 2010; Zhao et al., 2006; Bindi et al., 2014) were used for all models to obtain and compare the maps.

sists of a truncated normal distribution centred on the maximum magnitude. Other MFDs have been proposed to model the earthquake recurrence of a fault. For example, Youngs and Coppersmith (1985) proposed a modification to the truncated exponential model to allow for the increased likelihood of characteristic events. However, we focused only on two models, as we believe that instead of a "blind" or qualitative characterization of the MFD of a fault source, future application of statistical tests of the compatibility between expected earthquake rates and observed historical seismicity could be used as an objective method of identifying the optimal MFD of expected seismicity. As shown in this analyses, fault sources, even if modelled by TGR or CHG MFD, are able to match occurred seismicity for magnitude $\sim>5.5$ (see for example Fig. 8) and so are complementary to other inputs that model seismicity using area sources or smoothing approaches.

To focus on the general procedure for spatially integrating faults with sources representing distributed (or off-fault) seismicity, we did not investigate the impact of other smoothing procedures on the distributed sources, and we used fixed kernels with a constant bandwidth (as in the works of Kagan and Jackson, 1994; Frankel et al., 1997; Zechar and Jordan, 2010). The testing of adaptive bandwidths (e.g. Stock and Smith, 2002a, b; Helmstetter et al., 2006, 2007; Werner et al., 2010; Hiemer et al., 2014) or weighted combinations of both models has been reserved for future studies.
Finally, we compared, as shown in Fig. 14, the 2013 European Seismic Hazard Model (ESHM13) developed within the SHARE project, the current Italian national seismic hazard map (MPS04), and the results of our model (mixed model) using the same GMPEs as used in this study. Specifically, for ESHM13, we compared the results to the fault-based hazard map (FSBG model) that accounts for fault sources and background seismicity. The figure shows how the impact of our fault sources is more evident than in FSBG-ESHM13, and the comparison with MPS04 confirms a similar pattern, but with some significant differences at the regional to local scales.

The strength of our approach lies in the integration of different levels of information regarding the active faults in Italy, but the final result is unavoidably linked to the quality of the relevant data. Our work focused on presenting and applying a new approach for evaluating seismic hazards based on active faults and intentionally avoided the introduction of uncertainties due to the use of different segmentation rules or other slip rate values of faults. Moreover, the impact of ground motion predictive models is important in seismic hazard assessment but beyond the scope of this work. Future steps will be devoted to analysing these uncertainties and evaluating their impacts on seismic hazard estimates. 


\section{Conclusions}

We presented a seismogenic source model for Italy, which summarizes and integrates the fault-based models developed within the last decade (Pace et al., 2006).

The model proposed in this study combines fault source inputs based on over 110 faults grouped into 86 fault sources and distributed source inputs. For each fault source, the maximum magnitude and its uncertainty were derived by applying scaling relationships, and the rates of seismic activity were derived by applying slip rates to seismic moment evaluations and balancing these seismic moments using two MFD models.

To account for unknown faults, a distributed seismicity input was applied following the well-known Frankel (1995) methodology to calculate seismicity parameters.

The fault sources and gridded distributed seismicity sources have been integrated via a new approach based on the idea that deformation in the vicinity of an active fault is concentrated along the fault and that the seismic activity in the surrounding region is reduced. In particular, a distancedependent linear weighting function has been introduced to allow the contribution of distributed sources (in the magnitude range overlapping the MFD of each fault source) to linearly decrease from 1 to 0 with decreasing distance from a fault. The strength of our approach lies in the ability to integrate different levels of available information for active faults that actually exist in Italy (or elsewhere), but the final result is unavoidably linked to the quality of the relevant data. We think that our seismogenic source model includes significant advances in the use of integrated active fault and seismological data.

The probabilistically estimated ground shaking maps produced using our model show a hazard pattern similar to that of the current maps at the national scale, but some significant differences in hazard level are present at the regional to local scales (Fig. 13).

Moreover, the impact using different MFD models to derive seismic activity rates has on the hazard maps was investigated. The PGA values in the hazard maps obtained with the TGR model are higher than those in the hazard maps based on the CHG model. This difference is because the rates of earthquakes with magnitudes from 5.5 to approximately 6 are generally higher in the TGR model than in the CHG model. Moreover, the relative contributions of fault source inputs and distributed source inputs have been identified in maps and profiles in three sectors of the study area. These profiles show that the hazard level is generally higher where fault inputs are used, and for high probabilities of exceedance, the contribution of distributed inputs equals that of fault inputs.

Finally, the mixed model was created by selecting the most appropriate MFD model for each fault. All data, including the locations and parameters of fault sources, are provided in the Supplement of this paper.
It shall be noted that our new seismogenic source model is not intended to replace, integrate, or assess the current official national seismic hazard model of Italy. While some aspects remain to be implemented in our approach (e.g. the integration of reverse/thrust faults in the database, sensitivity tests for the distance-dependent linear weighting function parameters, sensitivity tests for potential different segmentation models, and fault source inputs that account for fault interactions), the proposed model represents advancements in terms of input data (quantity and quality) and methodology based on a decade of research in the field of fault-based approaches to regional seismic hazard modelling.

Data availability. The implementation information of the codes FiSH and OpenQuake is available with the current releases (http:// fish-code.com, last accessed January 2016; https:/github.com/gem/ oq-engine, last accessed 30 September 2017). Other details of the fault source input are provided in Valentini et al. (2017) and can be provided on demand.

\section{The Supplement related to this article is available online at https://doi.org/10.5194/nhess-17-2017-2017- supplement.}

Competing interests. The authors declare that they have no conflict of interest.

Special issue statement. This article is part of the special issue "Linking faults to seismic hazard assessment in Europe". It is not associated with a conference.

Acknowledgements. We warmly thank the two reviewers, Laurentiu Danciu and Kris Vanneste, and the associated editor, Laura Peruzza, for their detailed and highly instructive reviews. This work was funded by Fondi Dipartimento DiSPUTer (B. Pace, responsible for "ex $60 \%$ " fund) and by the Italian Ministry of Education and Research (MIUR) funded project "High-resolution investigations for the assessment of seismic hazard and risk in the area affected by the earthquake of 6 April 2009" (FIRB-Abruzzo), code: RBAP10ZC8K 006.

Edited by: Laura Peruzza

Reviewed by: Kris Vanneste and Laurentiu Danciu

\section{References}

Akinci, A., Galadini, F., Pantosti, D., Petersen, M., Malagnini, L., and Perkins, D.: Effect of Time Dependence on Probabilistic Seismic-Hazard Maps and Deaggregation for the Central Apennines, Italy, B. Seismol. Soc. Am., 99, 585-610, 2009. 
Akkar, S., Sandikkaya, M. A., and Bommer, J. J.: Empirical Ground-Motion Models for Point and Extended-Source Crustal Earthquake Scenarios in Europe and the Middle East, Bulletin of Earthquake Engineering, ISSN:1570-761X, 2013.

Benedetti, L., Manighetti, I., Gaudemer, Y., Finkel, R., Malavieille, J., Pou, K., Arnold, M., Aumaitre, G., Bourles, D., and Keddadouche, K.: Earthquake synchrony and clustering on Fucino faults (Central Italy) as revealed from in situ Cl-36 exposure dating, J. Geophys. Res.-Sol. Ea., 118, 4948-4974, 2013.

Bindi, D., Massa, M., Luzi, L., Ameri, G., Pacor, F., Puglia, R., and Augliera, P.: Pan-European ground-motion prediction equations for the average horizontal component of PGA, PGV, and $5 \%$ damped PSA at spectral periods up to $3.0 \mathrm{~s}$ using the RESORCE dataset (Vol. 12, p. 391, 2014), B. Earthq. Eng., 12, 431-448, 2014.

Boncio, P., Brozzetti, F., and Lavecchia G.: Architecture and seismotectonics of a regional Low-Angle Normal Fault zone in Central Italy, Tectonics, 19, 1038-1055, 2000.

Boncio, P., Lavecchia, G., and Pace, B.: Defining a model of 3D seismogenic sources for Seismic Hazard Assessment applications: The case of central Apennines (Italy), J. Seismol., 8, 407425, 2004.

Boncio, P., Pizzi, A., Cavuoto, G., Mancini, M., Piacentini, T., Miccadei, E., Cavinato, G. P., Piscitelli, S., Giocoli, A., Ferretti, G., De Ferrari, R., Gallipoli, M. R., Mucciarelli, M., Di Fiore, V., Franceschini, A., Pergalani, F., Naso, G., and Macroarea, W. G.: Geological and geophysical characterisation of the Paganica San Gregorio area after the April 6, 2009 L'Aquila earthquake (M-w 6.3, central Italy): implications for site response, B. Geofis. Teor. Appl., 52, 491-512, 2011.

Bull, J. M., Barnes, P. M., Lamarche, G., Sanderson, D. J., Cowie, P. A., Taylor, S. K., and Dix, J. K.: High-resolution record of displacement accumulation on an active normal fault: implications for models of slip accumulation during repeated earthquakes, J. Struct. Geol., 28, 1146-1166, 2006.

Chiou, B. S. J. and Youngs, R. R.: An NGA model for the average horizontal component of peak ground motion and response spectra, Earthq. Spectra, 24, 173-215, 2008.

Cornell, C. A.: Engineering seismic risk analysis, B. Seismol. Soc. Am., 58, 1583-1606, 1968.

Cowie, P. A.: A healing-reloading feedback control on the growth rate of seismogenic faults, J. Struct. Geol., 20, 1075-1087, 1998.

Cowie, P. A., Vanneste, C., and Sornette, D.: Statistical Physics Model for the Spatiotemporal Evolution of Faults, J. Geophys. Res.-Sol. Ea., 98, 21809-21821, 1993.

Cowie, P. A., Underhill, J. R., Behn, M. D., Lin, J., and Gill, C. E.: Spatio-temporal evolution of strain accumulation derived from multi-scale observations of Late Jurassic rifting in the northern North Sea: A critical test of models for lithospheric extension, Earth Planet Sc. Lett., 234, 401-419, 2005.

Cowie, P. A., Roberts, G. P., Bull, J. M., and Visini, F.: Relationships between fault geometry, slip rate variability and earthquake recurrence in extensional settings, Geophys. J. Int., 189, 143-160, 2012.

D’Amato, D., Pace, B., Di Nicola, L., Stuart, F. M., Visini, F., Azzaro, R., Branca, S., and Barfod, D. N.: Holocene slip rate variability along the Pernicana fault system (Mt. Etna, Italy): Evidence from offset lava flows: GSA Bulletin, 129, 304-317, https://doi.org/10.1130/B31510.1, 2016.
Danciu, L., Şeşetyan, K., Demircioglu, M., Gülen, L., Zare, M., Basili, R., Elias, A., Adamia, S., Tsereteli, N., Yalçin, H., Utkucu, M., Khan, M. A., Sayab, M., Hessami, K., Rovida, A. N., Stucchi, M., Burg, J. P., Karakhanian, A., Babayan, H., Avanesyan,M., Mammadli, T., Al-Qaryouti, M., Kalafat, D., Varazanashvili, O., Erdik, M., and Giardini, D.: The 2014 Earthquake Model of the Middle East: seismogenic sources, B. Earthq. Eng., 1-32, https://doi.org/10.1007/s10518-017-0096-8, 2017.

Faccioli, E., Bianchini, A., and Villani, M.: New ground motion prediction equations for $t>1 \mathrm{~s}$ and their influence on seismic hazard assessment, in: Proceedings of the University of Tokyo symposium on long-period ground motion and urban disaster mitigation, 17-18 March, University of Tokyo, Tokyo, Japan, 2010.

Ferranti, L., Palano, M., Cannavo, F., Mazzella, M. E., Oldow, J. S., Gueguen, E., Mattia, M., and Monaco, C.: Rates of geodetic deformation across active faults in southern Italy, Tectonophysics, 621, 101-122, 2014.

Field, E. H., Jackson, D. D., and Dolan, J. F.: A mutually consistent seismic-hazard source model for southern California, B. Seismol. Soc. Am., 89, 559-578, 1999.

Field, E. H., Biasi, G. P., Bird, P., Dawson, T. E., Felzer, K. R., Jackson, D. D., Johnson, K. M., Jordan, T. H., Madden, C., Michael, A. J., Milner, K. R., Page, M. T., Parsons, T., Powers, P. M., Shaw, B. E., Thatcher, W. R., Weldon, R. J., and Zeng, Y. H.: Long-Term Time-Dependent Probabilities for the Third Uniform California Earthquake Rupture Forecast (UCERF3), B. Seismol. Soc. Am., 105, 511-543, 2015.

Field, E. H., Jordan, T. H., Page, M. T., Milner, K. R., Shaw, B. E., Dawson, T., Biasi, G. P., Parsons, T., Hardebeck, J. L., Michael, A. J., Weldon, R. J., Powers, P. M., Johnson, K. M., Zeng, Y., Bird, P., Felzer, K. R., van der Elst, N. J., Madden, C., Arrowsmith, R., Werner, M. J., Thatcher, W. R., and Jackson, D. D.: A Synoptic View of the Third Uniform California Earthquake Rupture Forecast (UCERF3), Seismol. Res. Lett., 88, 1259-1267, https://doi.org/10.1785/0220170045, 2017.

Finnegan, N. J., Schumer, R., and Finnegan, S.: A signature of transience in bedrock river incision rates over timescales of 10(4)-10(7) years, Nature, 505, 391-394, https://doi.org/10.1038/nature12913, 2014.

Frankel, A.: Simulating Strong Motions of Large Earthquakes Using Recordings of Small Earthquakes - the Loma-Prieta Mainshock as a Test-Case, B. Seismol. Soc. Am., 85, 1144-1160, 1995.

Frankel, A., Mueller, C., Barnhard, T., Perkins, D., Leyendecker, E. V., Dickman, N., Hanson, S., and Hopper, M.: Seismic-hazard maps for California, Nevada, and Western Arizona/Utah', U.S. Geological Survey Open-File Rept. 97-130, 1997.

Gallen, S. F., Pazzaglia, F. J., Wegmann, K. W., Pederson, J. L., and Gardner, T. W.: The dynamic reference frame of rivers and apparent transience in incision rates, Geology, 43, 623-626, 2015.

Garcia-Mayordomo, J., Gaspar-Escribano, J. M., and Benito, B.: Seismic hazard assessment of the Province of Murcia (SE Spain): analysis of source contribution to hazard, J. Seismol., 11, 453471, 2007.

Gardner, J. K. and Knopoff, L.: Is the sequence of earthquakes in Southern California, with aftershocks removed, Poissonian?, B. Seismol. Soc. Am., 64, 1363-1367, 1974. 
Gardner, T. W., Jorgensen, D. W., Shuman, C., and Lemieux, C. R.: Geomorphic and Tectonic Process Rates - Effects of Measured Time Interval, Geology, 15, 259-261, 1987.

Gasperini, P., Bernardini, F., Valensise, G., and Boschi, E.: Defining Seismogenic Sources from Historical Earthquake Felt Reports, B. Seismol. Soc. Am., 89, 94-110, 1999.

Gunderson, K. L., Anastasio, D. J., Pazzaglia, F. J., and Picotti, V.: Fault slip rate variability on 10(4)-10(5) yr timescales for the Salsomaggiore blind thrust fault, Northern Apennines, Italy, Tectonophysics, 608, 356-365, 2013.

Hanks, T. C. and Kanamori, H.: A moment magnitude scale, J. Geophys. Res., 84, 2348-2350, 1979.

Helmstetter, A., Kagan, Y. Y., and Jackson, D. D.: Comparison of short-term and time-independent earthquake forecast models for southern California, B. Seismol. Soc. Am., 96, 90-106, 2006.

Helmstetter, A., Kagan, Y. Y., and Jackson, D. D.: High-resolution time-independent grid-based forecast for $M<=5$ earthquakes in California, Seismol. Res. Lett., 78, 78-86, 2007.

Hiemer, S., Woessner, J., Basili, R., Danciu, L., Giardini, D., and Wiemer, S.: A smoothed stochastic earthquake rate model considering seismicity and fault moment release for Europe, Geophys. J. Int., 198, 1159-1172, https://doi.org/10.1093/gji/ggu186, 2014.

IASPEI (International Association of Seismology and Physics of the Earth's Interior): Summary of Magnitude Working Group recommendations on standard procedures for determining earthquake magnitudes from digital data, available at: ftp://ftp.iaspei.org/pub/commissions/CSOI/summary_ of_WG_recommendations_2005.pdf (last access: December 2015), 2005.

Kagan, Y. Y.: Seismic moment distribution revisited: I. Statistical results, Geophys. J. Int., 148, 520-541, 2002.

Kagan, Y. and Knopoff, L.: Earthquake risk prediction as a stochastic process, Phys. Earth Planet. Int., 14, 97-108, 1977.

Kagan, Y. Y. and Jackson, D. D.: Long-Term Probabilistic Forecasting of Earthquakes, J. Geophys. Res.-Sol. Ea., 99, 13685-13700, 1994.

Kagan, Y. Y., Jackson, D. D., and Geller, R. J.: Characteristic earthquake model, 1884-2011, R.I.P., Seismol. Res. Lett., 83, 951953, 2012.

Kamer, Y. and Hiemer, S.: Data-driven spatial $b$ value estimation with applications to California seismicity: To $b$ or not to $b$, J. Geophys. Res.-Sol. Ea., 120, 5191-5214, 2015.

King, G. C. P., Stein, R. S., and Lin, J.: Static Stress Changes and the Triggering of Earthquakes, B. Seismol. Soc. Am., 84, 935-953, 1994.

Kostrov, V. V.: Seismic moment and energy of earthquakes, and seismic flow of rock, Physic of the Solid Earth, 1, 23-44, 1974.

Leonard, M.: Earthquake fault scaling: Self-consistent relating of rupture length, width, average displacement, and moment release, B. Seismol. Soc. Am., 100, 1971-1988, 2010.

Machette, M. N.: Active, capable, and potentially active faults; a paleoseismic perspective, J. Geodyn., 29, 387-392, 2000.

Main, I.: Statistical physics, seismogenesis, and seismic hazard, Rev. Geophys., 34, 433-462, 1996.

Mansfield, C. and Cartwright, J.: Fault growth by linkage: observations and implications from analogue models, J. Struct. Geol., 23, 745-763, 2001.
Meletti, C., Visini, F., D’Amico, V., and Rovida A.: Seismic hazard in central Italy and the 2016 Amatrice earthquake, Ann. Geophys., 59, https://doi.org/10.4401/ag-7248, 2016.

McClymont, A. F., Villamor, P., and Green, A. G.: Assessing the contribution of off-fault deformation to slip-rate estimates within the Taupo Rift, New Zealand, using 3-D ground-penetrating radar surveying and trenching, Terra Nova, 21, 446-451, 2009a.

McClymont, A. F., Villamor, P., and Green, A. G.: Fault displacement accumulation and slip rate variability within the Taupo Rift (New Zealand) based on trench and 3D ground-penetrating radar data, Tectonics, 28, TC4005, https://doi.org/10.1029/2008TC002334, 2009b.

Nicol, A., Walsh, J. J., Watterson, J., and Underhill, J. R.: Displacement rates of normal faults, Nature, 390, 157-159, 1997.

Nicol, A., Walsh, J., Berryman, K., and Villamor, P.: Interdependence of fault displacement rates and paleoearthquakes in an active rift, Geology, 34, 865-868, 2006.

Nicol, A., Walsh, J., Mouslopoulou, V., and Villamor, P.: Earthquake histories and Holocene acceleration of fault displacement rates, Geology, 37, 911-914, 2009.

Nicol, A., Walsh, J. J., Villamor, P., Seebeck, H., and Berryman, K. R.: Normal fault interactions, paleoearthquakes and growth in an active rift, J. Struct. Geol., 32, 1101-1113, 2010.

Ordaz, M. and Reyes, C.: Earthquake hazard in Mexico City: Observations versus computations, B. Seismol. Soc. Am., 89, 13791383, 1999.

Pace, B., Peruzza, L., Lavecchia, G., and Boncio, P.: Layered seismogenic source model and probabilistic seismic-hazard analyses in central Italy, B. Seismol. Soc. Am., 96, 107-132, 2006.

Pace, B., Bocchini, G. M., and Boncio, P.: Do static stress changes of a moderate-magnitude earthquake significantly modify the regional seismic hazard? Hints from the L'Aquila 2009 normalfaulting earthquake $\left(M_{\mathrm{W}} 6.3\right.$, central Italy), Terra Nova, 26, 430 439, 2014.

Pace, B., Visini, F., and Peruzza, L.: FiSH: MATLAB Tools to Turn Fault Data into Seismic-Hazard Models, Seismol. Res. Lett., 87, 374-386, 2016.

Pagani, M., Monelli, D., Weatherill, G., Danciu, L., Crowley, H., Silva, V., Henshaw, P., Butler, L., Nastasi, M. Panzeri, L., Simionato, M., and Vigano, D.: OpenQuakeengine: an open hazard (and risk) software for the Global Earthquake Model, Seismol. Res. Lett., 85, 692-702, https://doi.org/10.1785/0220130087, 2014.

Peruzza, L. and Pace, B.: Sensitivity analysis for seismic source characteristics to probabilistic seismic hazard assessment in central Apennines (Abruzzo area), B. Geofis. Teor. Appl., 43, 79100, 2002.

Peruzza, L., Pace, B., and Visini, F.: Fault-Based Earthquake Rupture Forecast in Central Italy: Remarks after the L'Aquila Mw 6.3 Event, B. Seismol. Soc. Am., 101, 404-412, 2011.

Peruzza, L., Gee, R., Pace, B., Roberts, G., Scotti, O., Visini, F., Benedetti, L., and Pagani, M.: PSHA after a strong earthquake: hints for the recovery, Ann. Geophys., 59, https://doi.org/10.4401/ag-7257, 2016.

Roberts, G. P. and Michetti, A. M.: Spatial and temporal variations in growth rates along active normal fault systems: an example from The Lazio-Abruzzo Apennines, central Italy, J. Struct. Geol., 26, 339-376, 2004. 
Roberts, G. P., Cowie, P., Papanikolaou, I., and Michetti, A. M.: Fault scaling relationships, deformation rates and seismic hazards: an example from the Lazio-Abruzzo Apennines, central Italy, J. Struct. Geol., 26, 377-398, 2004.

Robinson, R., Nicol, A., Walsh, J. J., and Villamor, P.: Features of earthquake occurrence in a complex normal fault network: Results from a synthetic seismicity model of the Taupo Rift, New Zealand, J. Geophys. Res.-Sol. Ea., 114, B12306, https://doi.org/10.1029/2008JB006231, 2009.

Rovida, A., Locati, M., Camassi, R., Lolli, B., and Gasperini P.: CPTI15, the 2015 version of the Parametric Catalogue of Italian Earthquakes, Istituto Nazionale di Geofisica e Vulcanologia, https://doi.org/10.6092/INGV.IT-CPTI15, 2016.

Scotti, O., Clement, C., and Baumont, D.: Seismic hazard for design and verification of nuclear installations in France: regulatory context, debated issues and ongoing developments, B. Geofis. Teor. Appl., 55, 135-148, 2014.

Stein, R. S., King, G. C. P., and Lin, J.: Stress Triggering of the 1994 $M=6.7$ Northridge, California, Earthquake by Its Predecessors, Science, 265, 1432-1435, 1994.

Stirling, M., McVerry, G., Gerstenberger, M., Litchfield, N., Van Dissen, R., Berryman, K., Barnes, P., Wallace, L., Villamor, P., Langridge, R., Lamarche, G., Nodder, S., Reyners, M., Bradley, B., Rhoades, D., Smith, W., Nicol, A., Pettinga, J., Clark, K., and Jacobs, K.: National Seismic Hazard Model for New Zealand: 2010 Update, B. Seismol. Soc. Am., 102, 1514-1542, 2012.

Stock, C. and Smith, E. G. C.: Adaptive kernel estimation and continuous probability representation of historical earthquake catalogs, B. Seismol. Soc. Am., 92, 904-912, 2002a.

Stock, C. and Smith, E. G. C.: Comparison of seismicity models generated by different kernel estimations, B. Seismol. Soc. Am., 92, 913-922, 2002b.

Stucchi, M., Meletti, C., Montaldo, V., Crowley, H., Calvi, G. M., and Boschi, E.: Seismic Hazard Assessment (2003-2009) for the Italian Building Code, B. Seismol. Soc. Am., 101, 1885-1911, 2011.
Verdecchia, A. and Carena, S.: Coulomb stress evolution in a diffuse plate boundary: 1400 years of earthquakes in eastern California and western Nevada, USA, Tectonics, 35, 1793-1811, 2016.

Visini, F. and Pace, B.: Insights on a Key Parameter of Earthquake Forecasting, the Coefficient of Variation of the Recurrence Time, Using a Simple Earthquake Simulator, Seismol. Res. Lett., 85, 703-713, 2014.

Weichert, D. H: Estimation of the earthquake recurrence parameters for unequal observation periods for different magnitudes, B. Seismol. Soc. Am., 70, 1337-1346, 1980.

Wells, D. L. and Coppersmith, K. J.: New Empirical Relationships among Magnitude, Rupture Length, Rupture Width, Rupture Area, and Surface Displacement, B. Seismol. Soc. Am., 84, 974-1002, 1994.

Werner, M. J., Helmstetter, A., Jackson, D. D., Kagan, Y. Y., and Wiemer, S.: Adaptively smoothed seismicity earthquake forecasts for Italy, Ann. Geophys.-Italy, 53, 107-116, 2010.

Woessner, J., Laurentiu, D., Giardini, D., Crowley, H., Cotton, F., Grunthal, G., Valensise, G., Arvidsson, R., Basili, R., Demircioglu, M. B., Hiemer, S., Meletti, C., Musson, R. W., Rovida A. N., Sesetyan, K., Stucchi, M., and Consortium, S.: The 2013 European Seismic Hazard Model: key components and results, B. Earthq. Eng., 13, 3553-3596, 2015.

Youngs, R. R. and Coppersmith, K. J.: Implications of Fault Slip Rates and Earthquake Recurrence Models to Probabilistic Seismic Hazard Estimates, B. Seismol. Soc. Am., 75, 939-964, 1985.

Zechar, J. D. and Jordan, T. H.: Simple smoothed seismicity earthquake forecasts for Italy, Ann. Geophys.-Italy, 53, 99-105, 2010

Zhao, J. X., Zhang, J., Asano, A., Ohno, Y., Oouchi, T., Takahashi, T., Ogawa, H., Irikura, K., Thio, H. K., Somerville, P. G., Fukushima, Y., and Fukushima, Y.: Attenuation relations of strong ground motion in Japan using site classification based on predominant period, B. Seismol. Soc. Am., 96, 898-913, 2006. 